\title{
Inducers of Senescence, Toxic Compounds, and Senolytics: The Multiple Faces of Nrf2-Activating Phytochemicals in Cancer Adjuvant Therapy
}

\author{
Marco Malavolta $\left(\mathbb{D},{ }^{1}\right.$ Massimo Bracci $\left(\mathbb{D},{ }^{2}\right.$ Lory Santarelli $(\mathbb{D}),{ }^{2}$ Md Abu Sayeed, ${ }^{2}$ \\ Elisa Pierpaoli, ${ }^{1}$ Robertina Giacconi, ${ }^{1}$ Laura Costarelli, ${ }^{1}$ Francesco Piacenza, ${ }^{1}$ Andrea Basso, ${ }^{1}$ \\ Maurizio Cardelli, ${ }^{1}$ and Mauro Provinciali ${ }^{1}$ \\ ${ }^{1}$ Advanced Technology Center for Aging Research, Scientific Technological Area, Italian National Institute of Health and Science on \\ Aging (INRCA), Ancona 60121, Italy \\ ${ }^{2}$ Department of Clinical and Molecular Sciences, Polytechnic University of Marche, Ancona 60126, Italy
}

Correspondence should be addressed to Marco Malavolta; m.malavolta@inrca.it

Received 6 October 2017; Accepted 19 December 2017; Published 12 February 2018

Academic Editor: Johannes Grillari

Copyright (c) 2018 Marco Malavolta et al. This is an open access article distributed under the Creative Commons Attribution License, which permits unrestricted use, distribution, and reproduction in any medium, provided the original work is properly cited.

\begin{abstract}
The reactivation of senescence in cancer and the subsequent clearance of senescent cells are suggested as therapeutic intervention in the eradication of cancer. Several natural compounds that activate Nrf2 (nuclear factor erythroid-derived 2-related factor 2) pathway, which is involved in complex cytoprotective responses, have been paradoxically shown to induce cell death or senescence in cancer. Promoting the cytoprotective Nrf2 pathway may be desirable for chemoprevention, but it might be detrimental in later stages and advanced cancers. However, senolytic activity shown by some Nrf2-activating compounds could be used to target senescent cancer cells (particularly in aged immune-depressed organisms) that escape immunosurveillance. We herein describe in vitro and in vivo effects of fifteen Nrf2-interacting natural compounds (tocotrienols, curcumin, epigallocatechin gallate, quercetin, genistein, resveratrol, silybin, phenethyl isothiocyanate, sulforaphane, triptolide, allicin, berberine, piperlongumine, fisetin, and phloretin) on cellular senescence and discuss their use in adjuvant cancer therapy. In light of available literature, it can be concluded that the meaning and the potential of adjuvant therapy with natural compounds in humans remain unclear, also taking into account the existence of few clinical trials mostly characterized by uncertain results. Further studies are needed to investigate the therapeutic potential of those compounds that display senolytic activity.
\end{abstract}

\section{Introduction}

Cellular senescence (CS) is a biological response to a variety of stresses that results in persistent growth arrest with a distinct morphological and biochemical phenotype [1-3]. It is currently considered a "barrier" to prevent malignant transformation and a potent anticancer mechanism as well as a hallmark of aging. Exploration of CS to drive towards antitumor adjuvant therapies by natural compounds is currently gaining increasing interest. Cancer cells can be forced to undergo senescence by natural compounds, with effects somewhat comparable to those obtained by genetic and epigenetic manipulations, anticancer drugs, and irradiation [4]. These effects have been shown after sustained exposure in vitro to a wide range of different substances that are also paradoxically used to obtain cytoprotective and chemopreventive adaptive responses in normal cells $[5,6]$. Interestingly, most of these cytoprotective activities are likely to be mediated by Nrf2 (nuclear factor erythroid-derived 2 related factor 2) stress-responsive signaling [7-9]. Examples of these natural bioactive compounds include mostly phenols like curcumin, epigallocatechin gallate (EGCG), fisetin, genistein, 
phloretin, quercetin, resveratrol, and silybin as well as other classes of compounds such as organosulfur compounds [i.e., allicin, phenethyl isothiocyanate (PEITC), and sulforaphane], metyl-tocols [i.e., tocotrienols], alkaloids (i.e., berberine, piperlongumine), and terpenoids (i.e., triptolide) [9-12]. Although, in certain cases, these compounds can specifically interact with the altered pathways of cancer cells [5]; the structural and physical differences of these compounds suggest that their ability to activate the antioxidant response elements (AREs) of many cytoprotective genes through the cytoplasmic oxidative stress system, Nrf2-Keap1 (Kelch-like $\mathrm{ECH}$-associated protein 1), is perhaps a common mechanism of action. Considering that cancers with high Nrf2 levels are associated with poor prognosis because of radio and chemoresistance and aggressive proliferation, activating Nrf2 pathway is considered protective in the early stages of tumorigenesis but detrimental in the later stages [13]. Hence, it can be found a paradox on how Nrf2-activating compounds can be proposed to induce senescence in cancer cells and, eventually, as a tool for adjuvant therapy. Interestingly, it is becoming evident that some effects of Nrf2-Keap1 pathway may be mediated through crosstalk with additional pathways (i.e., the aryl hydrocarbon receptor (AhR) pathway) affecting aspects of cell fate that provide a multitiered, integrated response to chemical stresses [14] which, in turn, could eventually culminate in a senescent response. This could be promoted by defective pathways of cancer cells or by excess amounts of the bioactive compounds. Indeed, most of the prosenescence effects shown in vitro are obtained with relatively high concentrations of the bioactive compounds (micromolar ranges) that are likely to not be translated in vivo (usually nanomolar ranges) due to potential toxicity to healthy cells, unless the compound can be specifically targeted to cancer cells. Interestingly, selective accumulation of natural compounds (i.e. T3s) in cancer tissues has been reported [15] and would deserve appropriate investigation for the future development of adjuvant supplements in cancer therapy. The possibility to induce senescence in tumors with lower drug doses, especially if administered chronically, may potentially limit treatment-related toxic side effects. However, even in the cases where a sufficient degree of selectivity has been demonstrated, senescence escape systems of cancer cells [16] may hamper the efficacy and thus the clinical applications of these compounds. In addition, it is an emerging concept that immune responses against senescent cells are crucial to restrict disease progression in cancer pathologies [17]. Treatments aimed at inducing senescence in cancer are likely to fail in the complete clearance of senescent cancer cells if not supported by a proper senescence immune surveillance response [16]. Senescent cancer cells might later be able to revert their senescent phenotype [18] or promote new cancers in their microenvironment in the case of ineffective clearance mechanisms [19, 20]. In this case, the interaction of natural bioactive compounds with the senescent-associated secretory phenotype (SASP) might be crucial. The SASP may have positive or negative effects, depending on the context: it can cause local and potentially systemic inflammation, disrupt tissue architecture, and stimulate growth and survival of nearby malignant cells [17], but it can be eventually important to promote immune clearance of senescent cells. Hence, the anti-inflammatory activity of natural compounds should also be carefully evaluated in this context. Additional challenges in this field include the proper characterization of CS [21], a clear understanding of the role of senescent cells in physiological and pathological conditions [2] and the huge heterogeneity of CS models [22, 23] which, in turn, might make it difficult to compare the effects and understand the proper area of application of promising natural bioactive compounds. In this review, we summarize the most relevant studies focused on induction of CS in vitro by selected bioactive compounds and discuss critical aspects related to their putative mechanisms of action and eventual translation in vivo.

\section{Cellular Senescence and Senolytic Compounds}

CS is usually defined as a status of growth arrest mediated by insensibility to mitogen stimuli, chromatin and secretome changes, and upregulation of particular tumor suppressor pathways $[2,24,25]$. CS induction may occur by a variety of cell-intrinsic and cell-extrinsic stresses, including DNA damage, oxidative stress, critical telomere shortening and damage, chronic mitogenic signaling, oncogene activation and inactivation, loss of tumor suppressors, nucleolar stress, and epigenetic changes [25]. There is no unique and definitive marker to define the senescent status of a cell, and not all senescent cells show the same features. Hence, characterization of CS can be performed by assessing multiple markers such as an enlarged morphology, the activation of p53-p21 and/or p16-Rb tumor suppressor pathways, the presence of persistent DNA damage response (DDR), an increase in CS-associated beta-galactosidase (SA- $\beta-\mathrm{Gal})$ activity, and the appearance of senescent-associated distension of satellites and telomere-associated DNA damage foci. In replicative senescence, critically shortened telomeres activate DDR and subsequent stabilization of p53 while oxidative stress and oncogene-induced senescence may work mainly through the activation of both p53 and p16 pathways [2]. Epigenetic derepression of CDKN2A (cyclin-dependent kinase inhibitor 2A) locus, which encode for both p16 and p14, is another trigger for senescence associated with aging and is responsible of the increased expression of p16 in aged tissues [26] and one of the most prominent indicators of the presence of senescent cells in aged tissues [27]. A common mediator of CS is the inhibition of $\mathrm{Rb}$ phosphorylation, which results in the inactivation of the E2F transcription factor, and its target genes involved in cell cycle progression [28]. The activation of growth pathways, via the mTOR (mammalian target of rapamycin), and the autophagic response appear as additional important players in establishing CS [29]. Senescent cells additionally display an increase in metabolic activity and, frequently, develop the SASP, which includes several proteins involved in inflammation processes, proteases, hemostatic, and growth factors [30].

Studies of human tissues and cancer-prone mice argue strongly that CS is one of the most important processes to suppress cancer in vivo [24], but the SASP produced by 
senescent cells can induce deleterious effects in the microenvironment by damaging neighboring cells, thus facilitating tumor development and aggressiveness [31], mediating paracrine transmission of CS [32], and promoting age-related dysfunctions [25].

An important physiological function of the SASP is to promote clearance of senescent cells by the immune system (a process named senescence immunosurveillance). However, age-related immunodeficiency or the production of a less proinflammatory SASP by senescent cells accumulated in aged-tissues could hamper senescence immunosurveillance [25].

A relevant feature of some, but not all [33], senescent cells is their long-term survival and resistance to apoptosis [34], which likely contributes to their persistence and the respective deleterious consequences in aged tissues. A direct demonstration that senescent cells can drive age-related pathologies has been originally provided with the development of a transgenic mouse model, in which p16expressing cells can be specifically eliminated upon drug treatment, with consequent prevention, delay, or attenuation of some age-related disorders [35]. This study prompted the birth of a field of research aimed to identify antiapoptotic mechanisms occurring in senescent cells and the relative compounds that are able to break this resistance to cell death with a high selectivity for senescent cells. The development of this area of research has been so fast that research around compounds able to selectively induce death in senescent cells (named senolytic drugs) represents now one of the most fruitful area of investigation [36, 37]. Preclinical studies have reported that senolytic compounds can improve cardiac function [38] in old mice, recover vascular function and decrease vascular calcification in atherosclerosis mice [39], and improve pulmonary function and physical health in mouse models of fibrotic pulmonary disease [40], as well as achieve partial rejuvenation in several tissues of progeroid mice [38, 41]. Besides, these are only part of the results achieved in age-related chronic conditions and others are expected to be shown soon. Importantly, senescent cells accumulate in mice treated with chemotherapy, causing a range of defects and promoting tumor recurrence [42]. Hence, it is not surprising that senolytic compounds have been proven to delay tumor recurrence and metastasis in mouse cancer models after chemotherapy [42] as well as to ameliorate side effects associated with the therapy [43]. However, senolytic compounds appear to be cell type restricted as a consequence of the heterogeneity of senescent cells and their different antiapoptotic pathways. The most important antiapoptotic pathways identified in senescent cells include the B-cell lymphoma 2 (BCL-2)/B-cell lymphoma-extra large (Bcl-xL), the PI3k $\delta / A K T$, the p53/p21, the ephrins, the HIF$1 \alpha$, the HSP-90, and various metabolic pathways [37]. These pathways may be differentially activated depending on the type of senescent cells (e.g., endothelial cells or fibroblasts) and the species of the donor (e.g., human or mice); thus, each senolytic compound displays its activity in some but not all types of senescent cells. In certain cases, the combination of two compounds is effective as senolytic in a wider range of cell type than the single compounds. This is the case of the combination of quercetin with dasatinib, which is effective in several models of senescent cells (endothelial, preadipocytes, and fibroblasts), whereas quercetin is only effective in radiation-induced endothelial cells and dasatinib in senescent preadipocytes [38].

Up to date, a small number of natural compounds have been shown to display senolytic activity, but it is likely that this is the tip of an iceberg that will be exposed in the coming years. These include quercetin [38], fisetin [44], phloretin [45], and piperlongumine [46], and there are preliminary indications that tocotrienols [47] and, eventually, cannabinoids [6] may also display senolytic activity in particular models of cellular senescence. Paradoxically, and very similar to the activity of senescence inducers described in the previous section, all these compounds can be accumulated by their potential to induce Nrf2 cellular response, which has a well-demonstrated cytoprotective and antiapoptotic effects. Indeed, the Nrf2/Keap1 pathway is activated by quercetin [48], fisetin [49], piperlongumine [50], and phloretin [51] as well as by different cannabinoids [52], tocotrienols [53], and a multitude of anticarcinogenic natural compounds that were found to cause cancer cell apoptosis or senescence under certain conditions (Figure 1).

The molecular mechanisms explaining how the Nrf2/ Keap1 pathway is modulated during apoptosis and senescence are currently largely unknown, and this gap of knowledge may contribute to hamper the clinical translation of adjuvant therapies based on Nrf2-activating compounds.

\section{The Nrf2-Keap1 Pathway}

The Nrf2-Keap1 pathway is a key controller of cellular response to stress caused by reactive oxygen species (ROS) [13]. The Nrf2 antioxidant response is mediated by the activation of ARE/electrophile responsive element (ARE) in the regulatory region of target genes. Molecular details of this signaling pathway and its dysregulation in cancer have emerged over the last 10 years and are extensively reviewed elsewhere $[13,14,54]$. Oxidative signals induce changes in the sulfhydryl groups of Keap1, thus promoting Nrf2 dissociation from Keap1, Nrf2 nuclear translocation, and stimulate mRNA expression of Nrf2-targeted downstream genes. Genomic analyses indicate that gene families affected by Nrf2 display a multitude of responses with a defensive role against cellular senescence including detoxification, antioxidant, damage repair, and inhibition of inflammation. This response involves more than 200 antioxidant and protective genes that constitute the so-called phase II response. Among these enzymes, we can mention $\gamma$-glutamylcysteine ligase ( $\gamma$-GCL), glutathione peroxidase (GPx), heme oxygenase 1 (HO-1), superoxide dismutase (SOD), glutathione S-transferase (GST), and NADPH-quinone oxidoreductase (NQO1) which have been frequently studied in the context of a protective response against cell death or senescence [55]. Hence, it is not surprising that a body of evidence supports the role of Nrf2 in mediating protection against stressinduced senescence [55-58]. Several studies have identified inactivating mutations in Keap1, leading to an increase in Nrf2 function, in human cancers [59-61]. Hence, inducing 


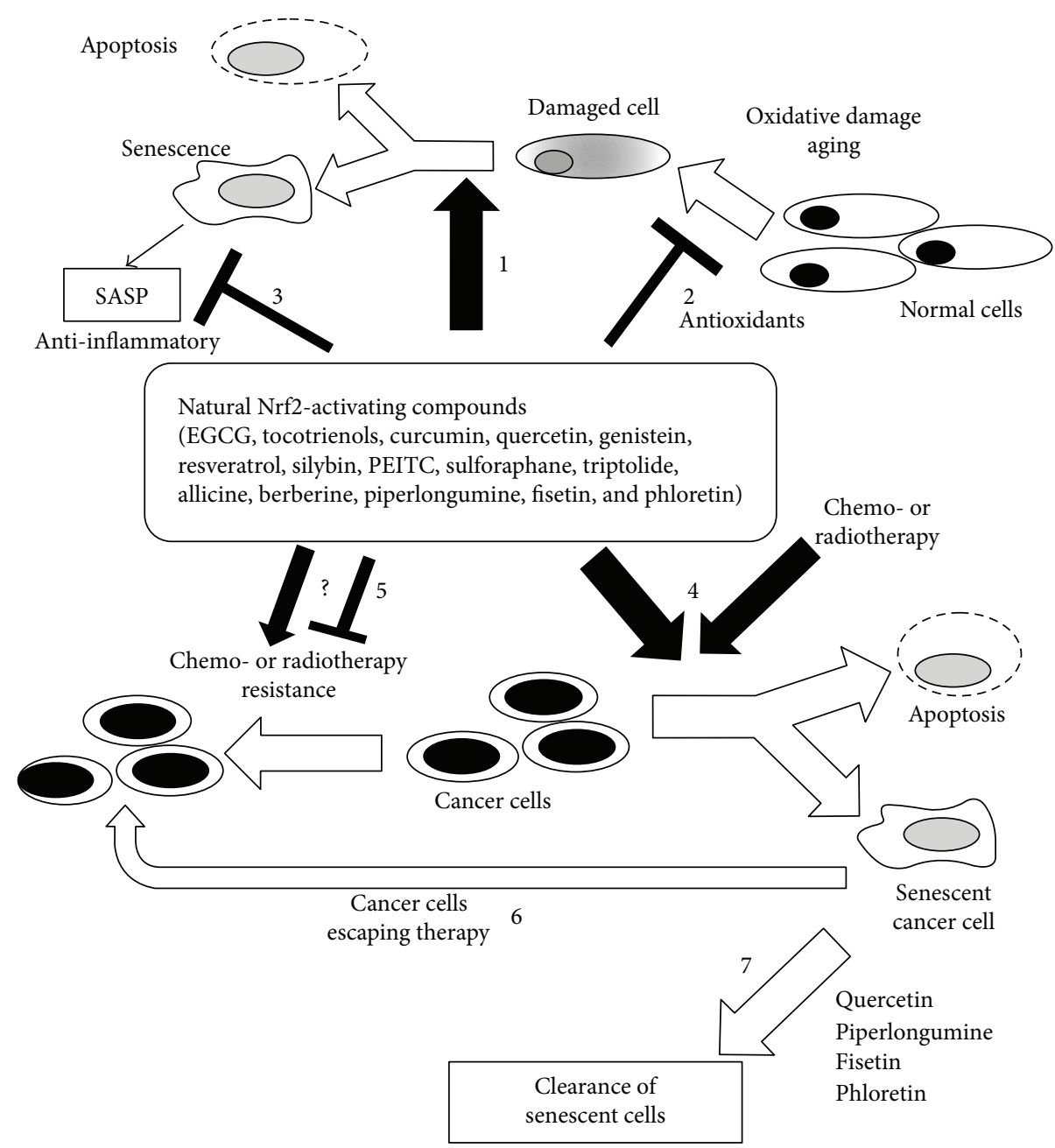

FIGURE 1: Potential effects and concerns of selected natural compounds as adjuvant in cancer therapy. Based on experiments "in vitro," epigallocatechin gallate (EGCG), tocotrienols, curcumin, quercetin, genistein, resveratrol, silybin, phenyl isothiocyanate (PEITC), sulforaphane, triptolide, allicin, berberine, piperlongumine, fisetin, phloretin might be useful in prevention and therapy of cancer. Geroand cancer preventive activity include (1) induction senescence or apoptosis in normal damaged and potentially precancerous cells, (2) protection of normal cells by damage via modulation of antioxidant/cytoprotective pathways, and (3) anti-inflammatory activity that might reduce negative effects of the senescence-associated secretory phenotype (SASP) produced by senescent cells. In cancer therapy, natural bioactive compound might help (4) to induce apoptosis and senescence in cancer cells thus helping to reduce dosage of chemoand radiotherapy while keeping efficacy. The major concern regards the possibility that these compounds might act as cytoprotective in some cancer cells (as in normal cells), thus aggravating the problem of resistance of cancer to therapy (5). However, failure to clearance senescent cells (6), as it might occur in immune-compromised subjects, might represent a serious challenge for these applications. Inclusion of additional strategies (7) with other natural compounds (i.e., phloretin, fisetin, piperlongumine, and quercetin) able to induce selective death of senescent cells should be evaluated in future preclinical studies to reduce relapses and side effects of chemo- or radiotherapy.

the Nrf2-regulated cytoprotective response could provide a selective advantage to tumor cells, raising the question of whether it is hazardous to elicit these changes in the context of interventions for cancer.

The role of Nrf2 in cellular senescence has been poorly studied. It is known by other models (cell lines and cancer cells) that Nrf2 upregulates most of the antiapoptotic mechanisms that have been shown to be repressed by senolytics, including natural compounds. In particular, HIF-1 alpha signaling is augmented by induction of the Nrf2 pathway, as demonstrated in hypoxia models [62]. Moreover, Nrf2 protein upregulates the antiapoptotic protein $\mathrm{Bcl}-2$ [63] and interacts with $\mathrm{p} 21$, which promotes the activation of the antioxidant response mediated by Nrf2 [64]. Hence, it would have been expected that Nrf2 is upregulated in cellular senescence. In contrast with this rationale, Nrf2 has a declined function in senescence of human fibroblasts [65], whereas its silencing leads to premature senescence $[65,66]$. Moreover, it appears to be downregulated in oncogene-induced senescence of transformed cell lines (in which senescence can be triggered by MEK activation) and upregulated when senescence is bypassed (GEO Accession: GDS1637, Profile GDS1637/201146_at) [67]. In contrast with the premature senescence induced by Nrf2, others have reported that deletion of Nrf2 in mouse embryonic fibroblasts is associated with immortalization [68]. Interestingly, these immortalized 
cells display a positive staining for SA- $\beta$-Gal, thus suggesting that deficiency in proteosomal degradation induced by Nrf2 deletion could be compensated, at least in part, by induction of lysosomal hydrolytic enzymes [68] that are similarly activated in several models of cellular senescence.

In the next chapters, we describe the most studied Nrf2inducing natural compounds that have been shown to act in vitro as toxic compounds in cancer cells and that can be used as senolytics or senescence inducers (or both). A particular focus on the doses used in the experiments and a short description of their eventual use in clinical trials is also provided as schematically represented in Figure 1.

\section{Nrf2-Activating Phytochemicals: Senescence Inducers, Senolytics, or Toxic Compounds for Cancer Cells}

4.1. Tocotrienols. Tocotrienols (T3s), members of the vitamin E family, are naturally occurring compounds composed of four different isomers: alpha $(\alpha)$, beta $(\beta)$, gamma $(\gamma)$, and delta $(\delta)$. These compounds are present in barley oil, coconut oil, corn oil, palm oil, rice bran oil, wheat germ, and annatto [69]. Cell culture studies suggest that T3s affects numerous pathways linked with tumorigenesis, including Nrf2 pathway $[47,53]$.

4.1.1. Tocotrienols as Toxic Compounds in Cancer. In the last years, T3s have been of increasing interest due to the discovery of their anticancer effects, not generally evident with tocopherol-rich vitamin E preparations [70]. Among the four isoforms of T3s, $\gamma$ and $\delta$ are those which have proven greater effectiveness in countering the proliferation of tumor cells. T3s can induce apoptosis in various types of mammary cancer cells by acting on mitochondrial or death receptormediated pathways [71, 72].

Further anticancer mechanisms of T3s including downregulation of mitogenic signal/survival factors and induction of paraptosis-like death have also been described in different cellular models.

4.1.2. Tocotrienols as Senescence Inducers. T3s have been additionally shown to induce cell cycle arrest and senescence-like phenotype in various cancer cells in vitro. Genes involved in cell cycle control, such as p21, p27, and p53, may represent the downstream effectors of T3s that affect the balance between signals that drive the cell into senescence or to death. In malignant mouse +SA mammary epithelial cells, $4 \mu \mathrm{M} \gamma$-tocotrienol significantly inhibited cell proliferation which was associated with reduction in cell cycle progression from $G_{1}$ to $S$, as evidenced by increased p27 level, and a corresponding decrease in cyclin D1, CDK (cyclin-dependent kinase) 2, CDK4, CDK6, and phospho$\mathrm{Rb}$ levels [73]. Similar results have been shown in HER-2 (human epidermal growth factor receptor 2) overexpressing cell lines with the upregulation of p53, p21, and p16 induced by mixtures of $\gamma$-T3s and $\delta$-T3s [72]. Interestingly, oral administration of $100 \mathrm{mg} / \mathrm{kg}$ annatto-T3 delayed the spontaneous onset of mammary tumor and reduced tumor number and size through enhancing in situ both apoptosis and senescence markers in a HER2/neu breast cancer mouse model [15], thus showing that the results obtained in vitro can be translated in vivo. In this mouse model, T3s have been shown to specifically accumulate in cancer tissues of HER2/ neu mice at a very high rate than observed in normal tissues.

T3s $(10-20 \mu \mathrm{M})$ have also been shown to inhibit telomerase by affecting hTERT (human telomerase reverse transcriptase) and c-Myc expression through PKC (protein kinase C) activity suppression in human colorectal adenocarcinoma cell lines [74]. By the way, c-Myc is known to induce epigenetic changes leading to transcriptional activation of genes that suppress key drivers of CS. The involvement of $\mathrm{PKC}$, whose isoforms are known to selectively mediate certain malignant phenotype including HER2-positive breast tumors [75], in the mechanisms of action of T3s might also contribute to explain why T3s can induce opposite effects (antisenescence) in normal human fibroblasts [76]. Another upstream target of T3s that could mediate senescent-like response or apoptosis in breast cancer cells is ERs (estrogen receptors) [77]. T3s display high affinity for ER $\beta$ and increase its translocation into the nucleus which, in turn, activates the expression of estrogen-responsive genes [MIC-1 (macrophage inhibitory cytokine-1), EGR-1 (early growth response protein 1), and cathepsin D] involved in growth arrest, altered morphology, and apoptosis of ER $\beta$ expressing breast cancer cells (MDA-MB-231 and MCF-7) [78]. Hence, the idea that these compounds might promote senescence in cancer cells while displaying antisenescence effects in normal cells sounds very promising in view of its potential clinical applications.

4.1.3. Tocotrienols as Potential Senolytics. Senolytic activity has not been tested for T3s. However, some metabolic and apoptotic pathways affected by these compounds in cancer cells overlap with those of other compounds that have been shown to display senolytic activity, such as quercetin [47]. Moreover, T3s have been shown to display rejuvenating effects which might in the end represent the net results of a senolytic activity on senescent cells and a selective survival of a subpopulation of nonsenescent cells in the culture.

4.1.4. Tocotrienols in Cancer Adjuvant Therapy. Despite the number of clinical trials conducted to examine the multifaceted health benefits of T3s $[79,80]$, very little is known about the efficacy of T3s as adjuvant supplements in cancer therapy. Pilot clinical trials on the synergistic effect of T3s and chemotherapy have been mainly addressed to test safety without any clear advantage for survival or other clinical endpoints $[81,82]$. However, measurements of T3s in malign and benign adipose breast tissues of a Malaysian population found that total T3s levels were lower in the malignant tissues compared to the benign ones [83]. These data reinforce the idea that T3s may provide some kind of protection against breast cancer but the circumstances and the modality of intervention would require further studies.

4.2. Curcumin. Curcumin, a component of turmeric rhizome, is another example of $\mathrm{Nrf2}$-activating compound [84, 85] 
that, in certain circumstances, acts as cytotoxic or prosenescence compound in cancer cells.

4.2.1. Curcumin as Toxic Compound in Cancer. Curcumin affects various biochemical and molecular cascades involved in cancer by acting on a multitude of molecular targets including NF- $\kappa \mathrm{B}$ (nuclear factor kappa-light-chain-enhancer of activated B cells), Akt, MAPK (mitogen-activated protein kinases), p53, Nrf2, Notch-1, JAK (Janus kinase)/STAT (signal transducer and activator of transcription), $\beta$-catenin, and AMPK ( $5^{\prime}$ adenosine monophosphate-activated protein kinase) [86]. A direct inhibition of mTORC1 (mammalian target of rapamycin complex 1) signaling [87] and induction of autophagic cell death [88] have also been claimed to explain the cytotoxic effects of curcumin in various cancer cells. However, the same mechanisms can also be responsible for the reversion of senescence and appearance of proliferating cells in irradiated apoptosis-resistant cells [89].

4.2.2. Curcumin as Senescence Inducer. Notwithstanding senescence-suppressive activity, there is substantial evidence that curcumin can induce senescence in different cancer models. This has been clearly shown in MCF-7 breast cancer cell line [90, 91], human colon cancer cells, [90, 92] and breast cancer-associated stromal fibroblasts [93]. Inhibition of telomerase activity, induction of p53, p21, and p16, and an increased autophagic response have been reported as the main mediators of this prosenescence activity of curcumin.

4.2.3. Curcumin as Potential Senolytic. Curcumin has been recently tested for a potential senolytic activity in senescent fibroblasts from Ercc1-/- mice showing no effect on senescent cells [41]. However, this kind of activity would deserve further experiments in different type of cells.

4.2.4. Curcumin in Cancer Adjuvant Therapy. The most likely explanation to this multitude of proposed mechanisms is that curcumin can display cell-specific effects, thus suggesting that adjuvant therapy with this compound could be most effective in certain type of cancer using appropriate delivery systems. Some promising effects have been observed in breast, prostate, lung, pancreatic, and colorectal cancer as well as in multiple myeloma [94]. Consistent with in vitro studies, curcumin administration has been shown to affect molecular targets involved in cancer. Presurgery curcumin administration in patients with colorectal cancer decreased serum TNF-alpha levels and increased cancer cell apoptosis, observed as enhanced p53 and Bcl-2, and decreased Bax expression in tumor tissues compared with control [95]. A decrease in NF- $\kappa \mathrm{B}$ and cyclooxygenase-2 (COX-2) expression and pSTAT3 activation was shown in peripheral blood mononuclear cells (PBMC) from patients with advanced pancreatic cancer receiving curcumin oral administration contemporary to gemcitabine-based chemotherapy [96]. Also, curcumin seems to be effective in protecting from side effects associated to chemo- and radiotherapy [97], though no biological evidence has been provided. In spite of these promising results, the paucity of well-controlled clinical trials, the poor bioavailability of curcumin and the limited effects reported by some investigators are currently a major limitation to the therapeutic use of curcumin.

4.3. Epigallocatechin Gallate. Epigallocatechin gallate (EGCG), the most active and major component of polyphenols in green tea, is known to be the principal contributor to the potential benefits of green tea to human health [98]. Hence, it is not surprising that EGCG and other tea catechins have been claimed of anticarcinogenic and antimutagenic activities [99]. The use of EGCG as a possible chemopreventive agent is supported by a number of studies regarding the ability of EGCG to modulate Nrf2-mediated cellular events $[100,101]$. There is also substantial evidence that EGCG can display antisenescence effects, as observed in mesenchymal stem cells $[101,102]$.

4.3.1. EGCG as Toxic Compound in Cancer. The cytoprotective effect of EGCG is apparently in contrast with a number of studies in cancer cells suggesting that induction of apoptosis could be the main mechanism of green tea to suppress cancer cell growth [103]. This paradoxical effect and the different effects shown in cancer versus primary cells could be related to their different metabolism including defects in the regulatory feedback that involves mTOR, p53, and AMPK [5] which are related to the epigenetic differences between cancer and normal cells $[104,105]$. EGCG has been shown to be able to induce dose-dependent (5-80 $\mu \mathrm{M})$ apoptotic cell death in estrogen receptor- (ER-) independent breast cancer cells via an increased Bax to Bcl-2 protein ratio and p53 expression [106]. Moreover, EGCG appears to be critical for cancer cell metabolism due to the inhibition of mitochondrial functions and the generation of a starvationlike condition that activates AMPK and its downstream effects, including inhibition of mTOR signaling [107] and the activation of a sustained autophagic response that can promote autophagic cell death [108].

4.3.2. EGCG as Senescence Inducer. Nontoxic concentrations $(15 \mu \mathrm{M})$ of EGCG shortened telomeres, increased SA- $\beta$-Gal staining, induced chromosomal abnormalities, and, most importantly, limited the lifespan of U937 monoblastoid leukemia and colon adenocarcinoma cell lines (HT29) [109]. Experiments in breast cancer (MCF-7) and promyelocytic leukemia (HL60) cell lines have confirmed an inhibitory activity on telomerase activity by EGCG [110]. Alterations in histone modifications, decreased methylation of hTERT promoter, and increased binding of the hTERT repressor E2F-1 at the promoter were proposed as mediators of the observed bioactivity [110].

4.3.3. EGCG as Potential Senolytic. Although there are studies that have indicated EGCG as a senomorphic (suppressor of senescent phenotype) compound in vitro with potential lifespan-extending effects in animal models [111], there is currently no evidence that EGCG can exert senolytic activity in selected type of senescent cells.

4.3.4. EGCG in Cancer Adjuvant Therapy. EGCG has also been proven to synergize with some anticancer agents and to ameliorate their deleterious side effects, which makes 
EGCG a suitable adjuvant in chemotherapy [112]. However, most of the studies on this topic are preclinical, and several limitations in terms of stability, efficacy, and bioavailability have currently hampered the application of EGCG in clinical settings [113]. There are contrasting results depending on the type of cancer and therapy. For example, EGCG was shown to provide regression of esophagitis in patients with unresectable stage III non-small-cell lung cancer under chemo- and radiotherapy [114]. Conversely, green tea polyphenols may have the potential to negate the therapeutic efficacy of the boronic acid-based synthetic anticancer drug bortezomib, thus suggesting that EGCG may be contraindicated during cancer therapy with bortezomib [115]. Finally, it is important to note that the concentrations of EGCG used in vitro (tens of micromolar) are usually far from levels observed in serum after drinking few cups of tea as biologically achievable concentrations were generally reported to be below $1 \mu \mathrm{M}$ [116].

4.4. Quercetin. Quercetin is a member of flavonoid found in many dietary plants such as apple, apricot, broccoli, Brussels sprout, cauliflower, grape, lettuce, onion, strawberry, tomato, and wolfberry [117]. Quercetin has been reported to have anti-inflammatory, antidiabetic, antiobesity, and anticancer activities [118, 119]. Quercetin is also widely known to exert antioxidative stress activity via activating Nrf2 signaling pathway [120-122]. It has been demonstrated that quercetin can display antisenescence activity in normal cells. Senescent fibroblasts treated with about $6 \mu \mathrm{M}$ of quercetin for 5 consecutive days were shown to restart proliferation compared to the control cultures [123].

4.4.1. Quercetin as Toxic Compound in Cancer. There are several studies that propose the use of quercetin to induce apoptotic and nonapoptotic forms of cell death in cancer cells [124, 125]. Various mechanisms have been claimed to explain the ability of quercetin to bypass apoptotic resistance of cancer cells. Most of the studies report that quercetin can target antiapoptotic kinases and selective oncogenes (such as Mcl-1, Ras, MEK, and PI3K) or upregulate tumor suppressor genes (p53, p21), which lead to the selective elimination of cancer cells [126]. There is also evidence for an involvement of heat shock response proteins (HSP) in the toxicity of quercetin for cancer cells. Various quercetin-treated tumor cell lines were not induced to show aggregation of HSP70 in the nuclei in response to heat shock, resulting in apoptosis [127].

4.4.2. Quercetin as Senescence Inducer. As shown for most Nrf2-activating compounds, the finding that, in certain circumstances, it is also possible to use quercetin to induce senescence in cancer cells is not surprising. Chronic administration of $25 \mu \mathrm{M}$ quercetin plus $10 \mu \mathrm{M}$ resveratrol was shown to induce a senescent-like growth arrest in human glioma cells [128]. The prosenescence activity of quercetin in the glioma cellular models is compatible, at least in part, with the inhibition of HDAC (histone deacetylases) [129]. Interestingly, this inhibitory activity on HDAC was not observed in normal astrocytes. Quercetin was also shown to activate and stabilize p53 by inhibiting its RNA degradation and protein ubiquitination in liver carcinoma cells (HepG2), thus promoting p21 expression and cyclin D1 suppression in favor of cell cycle arrest [130]. Hence, circumstances where p53 is not stabilized or where HDAC is over activated pave the way to a potential use of quercetin to induce senescence in cancer.

4.4.3. Quercetin as Potential Senolytic. Quercetin $(10 \mu \mathrm{M})$ was proven to induce death in radiation-induced senescent endothelial cells and senescent bone marrow-derived mouse mesenchymal stem cells [38]. Conversely, quercetin was found to lack senolytic efficacy in senescent preadipocytes and mouse embryonic fibroblasts. The combination of quercetin with the anticancer drug dasatinib was shown to be effective as senolytic in several types of senescent cells [38]. In the context of cancer therapy, the potential of quercetin (or its combination with dasatinib or other compounds) to induce death in cancer cells after therapy-induced senescence should deserve appropriate investigation. This could be useful to reduce adverse effects of chemotherapy and cancer relapse, which are promoted by therapy-induced cellular senescence [42].

4.4.4. Quercetin in Cancer Adjuvant Therapy. Excluding studies designed to test safety, availability, and metabolism of quercetin [131], its use in clinical trials as adjuvant therapy for cancer patients still need to be appropriately investigated. Interesting results have been observed regarding the modulation of cancer-related biomarkers in few patients with ovarian cancer and hepatoma [132]. Critical points that hamper the use of quercetin in these trials include the side effects of the pharmacological dose that need to be administered, the lack of specificity, and the identification of direct cellular targets.

4.5. Genistein. Genistein is an isoflavonoid compound present in some edible plants such as alfalfa, soybean, fava bean, psoralea, pea, green lentil, and lupine [133]. Genistein is known for antioxidant, anticancer, anti-inflammatory, antiobesity, and antidiabetes activities [134-136]. In addition, this compound can protect cells from injury, toxicity, and oxidative stress by activating $\mathrm{Nrf} 2[12,137,138]$. At relatively low concentrations $(1-10 \mu \mathrm{M})$, genistein has been shown to delay senescence in vascular smooth muscle cells [139] and to enhance telomerase activity in prostate cancer cells [140].

4.5.1. Genistein as Toxic Compound in Cancer. Genistein can induce apoptotic and nonapoptotic cell death in several models of cancer cells [141]. For example, in H460 nonsmall lung and MDA-MB-231 breast cancer cells as well as in HT29 colon cancer cells, genistein inhibits cell growth and induces apoptosis at concentration from 30 to $50 \mu \mathrm{M}$ [142-144]. Genistein at lower concentration $(10 \mu \mathrm{M})$ can also sensitize sarcoma and breast cancer cells to X-rayinduced cell death by inhibiting the double-strand break (DSB) repair pathways [145, 146].

4.5.2. Genistein as Senescence Inducer. Numerous studies have shown that genistein can induce the expression of tumor suppressor genes p53, p21, and p16 in cancer [134, 147-150] 
that mediate cell cycle arrest and senescent response. It has also been reported that genistein at pharmacological concentrations $(50 \mu \mathrm{M})$ inhibited telomerase activity in brain [KNS60, U251MG(KO), and ONS76], ovarian (SKOV-3), breast (MCF-7), and prostate (DU-145, LNCaP) cancer cells $[140,151]$.

4.5.3. Genistein as Potential Senolytic. There is no information about senolytic activity of genistein but its inhibitory effect on tyrosine kinase [152] (the same target of dasatinib) would deserve appropriate consideration.

4.5.4. Genistein in Cancer Adjuvant Therapy. The contrasting results obtained in a relatively narrow range of concentration suggest that the use in vivo of this compound might deserve particular caution. Genistein aglycone can eventually stimulate tumor cell proliferation and growth in mice that exhibit a deficient immune system [153]. Moreover, epidemiological studies have shown an inverse correlation between genistein intake and breast cancer risk [153].

4.6. Resveratrol. Resveratrol is a naturally occurring polyphenolic compound present in grapes, mulberries, peanuts, and red wine. It has been identified as a cancer chemopreventive agent, based on its safety and efficacy in experimental models of carcinogenesis [154]. The antitumor activity of resveratrol has been attributed to the inhibition of diverse cellular events associated with tumor initiation, promotion, and progression [155]. Inhibition of carcinogenesis and the chemopreventive effects of resveratrol might be related to the induction of Nrf2-mediated protective pathways [156].

4.6.1. Resveratrol as Toxic Compound in Cancer. In vitro studies suggest that resveratrol is able to induce growth inhibition and apoptosis in several tumor cell lines [157-159]. The $\mathrm{IC}_{50}$ value in five cell lines (Seg-1, HCE7, SW480, MCF7, and HL60) was attributed to be in the range of 70$150 \mu \mathrm{M}$ [160] and only three of these cell lines (MCF7, HL60, and Seg-1) started to show a significant reduction in cell viability at $50 \mu \mathrm{M}$.

4.6.2. Resveratrol as Senescence Inducer. Resveratrol represents also one of the most active natural compounds in inducing senescence in cancer cells, in particular at concentrations equal or below $50 \mu \mathrm{M}$. The increase in the activity and expression of senescence-associated effectors (e.g., p53 and p21) was observed in various cancer cells treated with resveratrol. Resveratrol has shown to be able to exert SIRT1-dependent inhibitory effects on gastric cancer by inducing senescence in cellular models, as evidenced by the increased protein levels of inhibitors of CDKs (p21 and p16) and SA- $\beta$-Gal staining in resveratrol-treated samples [161]. The inhibitory effect on gastric cancer was also confirmed in vivo using a nude mice xenograft model. This effect was abrogated after SIRT1 (sirtuin 1) depletion probably through an indirect regulation of involved genes. Evidence of the involvement of senescence-associated effectors in the resveratrol-mediated antitumor action has been shown in many other tumor cell lines [162-164]. As it happens for some drugs, even resveratrol would seem to hijack the fate of tumor cells towards antiproliferative pathways depending on the dose of treatment and this phenomenon appears to be important also in cancer prevention [165]. In particular experimental settings, there is evidence that resveratrol may act as a potent senescence inducer. It has been shown that micromolar doses $(10-50 \mu \mathrm{M})$ of resveratrol-treatment in non-small-cell lung cancer cells can lead to a significant increase in SA- $\beta$-Gal staining and enhanced p 53 and p 21 expression, suggesting that the anticancer effect of resveratrol is largely attributable to the induction of senescence [166]. Similar concentrations of resveratrol have been effective in reducing the telomerase activity in MCF-7 breast cancer cells, probably affecting posttranscriptional phosphorylation and nuclear translocation of the catalytic subunit hTERT [167]. In accordance with these results, inhibition of transcriptional hTERT expression was proposed as a mechanism to explain resveratrol-mediated inhibition of human colorectal carcinoma cell proliferation [168]. All the above results highlight the ability of resveratrol to modulate different pathways related with the complex machinery of CS depending on the tumor types and treatment conditions.

4.6.3. Resveratrol as Potential Senolytic. There is no reported senolytic activity for resveratrol. A recent high throughput screening of senotherapeutics in senescent Ercc1-/- mouse embryonic fibroblasts showed no effect (neither senolytic nor senomorphic) of resveratrol, but this could be due to the concentration tested (not clearly specified, but likely at $1 \mu \mathrm{M}$ as declared for other compounds) and the specific model used [41].

4.6.4. Resveratrol in Cancer Adjuvant Therapy. Lack of specificity, efficacy, and poor bioavailability is the major limitation for the use of resveratrol as adjuvant therapy in cancer. While in vitro resveratrol seems to be highly effective in overcoming chemoresistance (at concentration of 25$50 \mu \mathrm{M}$ ), for example, in the case of multiple myeloma cells [169], the clinical translation of these doses in clinical settings appears problematic. Indeed, an unacceptable safety profile and minimal efficacy were shown in a clinical trial performed with $5 \mathrm{~g}$ /day of SRT50 (a micronized oral formulation of resveratrol developed to improve bioavailability) combined with bortezomib in patients with relapsed/refractory multiple myeloma [170]. However, the same dose and formulation resulted safe when administered in patients with colorectal cancer and hepatic metastases [171], suggesting that a thorough patient cohort study should be defined before clinical applications.

4.7. Silybin. Silybin, a major active constituent of silymarin (extract of the milk thistle seeds), has been shown to have antioxidant and cytoprotective as well as antitumor effects. Moreover, several studies performed in C. elgans suggest that silybin may display antiaging activity, mainly based on counteracting age-related loss of proteostasis [172-174]. In analogy with other flavonoids, also in this case, the antioxidant and cytoprotective effects seem to be related to the activation of Nrf2 pathway [175]. 
4.7.1. Silybin as Toxic Compound in Cancer. Silybin was found to induce growth inhibition and apoptosis in different human and murine tumor cell lines and to potentiate the effects of doxorubicin, cisplatin, and carboplatin in vitro [176-178]. Fewer studies have been conducted on the antitumor effect exerted by in vivo supplementation with silybin or silymarin. Most data on the in vivo effects of these compounds, confirming a general anticancer activity, have been drawn from studies done in mice treated with carcinogens or in nude mice bearing human xenografts [4].

4.7.2. Silybin as Senescence Inducer. Study reported that IdB 1016 (silipide), a silybin-phosphatidylcholine complex with improved bioavailability, induced cellular senescence in mammary tumor cells of mice at $450 \mathrm{mg} / \mathrm{Kg}$, as demonstrated by SA- $\beta$-gal staining in cancer tissues. According to the same study, this complex (at concentration in the range of $10-50 \mu \mathrm{M}$ ) also induced cellular senescence and apoptosis in human breast SKBR3 cancer cell line, which were associated with increased expression of p53 [179].

4.7.3. Silybin as Potential Senolytic. There is currently no evidence for a senolytic activity of silybin. However, the cooccurrence of markers of apoptosis and senescence in breast cancer cells treated with silybin [179] would suggest appropriate investigation in this field.

4.7.4. Silybin in Cancer Adjuvant Therapy. Conversely to the lack of cancer tissue penetration observed in prostate cancer patients (receiving $13 \mathrm{~g}$ per day of silybin-phytosome) [180], administration of silybin-phosphatidylcholine, $2.8 \mathrm{~g}$ daily, 1 month before surgery, to patients with early breast cancer showed a selective accumulation of silybin in breast tumor tissue [181]. However, clear proof of clinical efficacy as adjuvant in cancer therapy is still lacking. A pilot study (administration of $2 \mathrm{~g}$ per day in 3 patients) in advanced hepatocellular carcinoma demonstrated the complete lack of benefits [182].

4.8. Phenethyl Isothiocyanate. Phenethyl isothiocyanate (PEITC) is a member of isothiocyanate distributed as gluconasturtiin in some cruciferous plants including broccoli, cabbage, cauliflower, horseradish, and watercress [105]. This compound has multiple pharmacological activities including anticancer activity [183]. It has been reported that PEITC exhibits antioxidant activity by affecting Nrf2 signaling pathway $[11,184]$.

4.8.1. PEITC as Toxic Compound in Cancer. PEITC (at 5$10 \mu \mathrm{M}$ ) induces apoptosis in several cell lines by a cancer cell-specific generation of ROS [185] that is related to mitochondrial deregulation and modulation of proteins like $\mathrm{Bcl} 2, \mathrm{BID}, \mathrm{BIM}$, and BAX, causing the release of cytochrome c into cytosol leading to apoptosis [183]. Other mechanisms by which PEITC induces apoptosis (at $50 \mu \mathrm{M}$ ) include the increase of DDB2 (damaged DNA-binding protein 2) expression, as observed in colon cancer cells (HCT 116) in vitro and in vivo [186], as well as the activation of the extrinsic apoptotic pathway (death receptor-mediated apoptosis), as observed in oral and cervical cancer cells [187].
4.8.2. PEITC as Senescence Inducer. Modulation of the senescence effectors p16, p53, and p21 as well as increased staining for SA- $\beta$-Gal by PEITC was observed in cancer cells at concentration from $4 \mu \mathrm{M}$ to $20 \mu \mathrm{M}[186,188-190]$. PEITC also downregulated telomerase in cervical cancer cells (HeLa) [189].

4.8.3. PEITC as Potential Senolytic. The potential for PEITC as senolytic agent has been tested in radiation-induced senescent WI-38 fibroblasts without any evidence of selective death in normal versus senescent cells (LD50 ratio $=1)$ [191].

4.8.4. Efficacy of PEITC in Cancer Adjuvant Therapy. Preclinical evidence suggests that combination of PEITC with conventional anticancer agents is also highly effective in improving overall efficacy [183]. There is a clinical trial showing that PEITC can be an inhibitor of lung carcinogenesis [192], but its relevance in adjuvant cancer therapy is still unknown.

4.9. Sulforaphane. Sulforaphane is one of the most potent phase II enzyme inducer isolated from edible cruciferous vegetables with potent activity against cancer progression [193]. This activity has been demonstrated at the level of chemoprevention, as well as at the level of therapy at various stages of cancer. Sulforaphane represents a strong activator of Nrf2Keap1 signaling pathway, enabling Nrf2 to escape Keap1dependent degradation and leading to stabilization and nuclear accumulation of Nrf2 [194]. Acting through the Nrf2 pathway, sulforaphane inhibited 7,12-dimethylben$\mathrm{z}$ (a)anthracene-induced skin tumorigenesis in mice [195]. At the same time, the Nrf2 pathway seems to be involved in the sulforaphane-mediated protection from apoptosis in different cellular models [196, 197]. Oral administration of sulforaphane was able to inhibit DMBA-induced mammary carcinogenesis in rats [198]. In this animal model, an accumulation of sulforaphane metabolites, followed by an increased expression in NQO1 and $\mathrm{HO}-1$ cytoprotective mRNAs, was observed in mammary gland after a single oral $150 \mu \mathrm{M}$ dose of sulforaphane. Interestingly, a local increase of SFN metabolites was observed in epithelial cells from human breast tissue after a single oral sulforaphane dose $(200 \mu \mathrm{M})$ in healthy women undergoing reduction mammoplasty. Hence, the specific intracellular accumulation and retention of this compound in mammary epithelium might contribute to protecting normal cells from tumor initiation and progression, though more large-scale clinical trials are needed to verify the effectiveness of sulforaphane as anticancer agent.

4.9.1. Sulforaphane as Toxic Compound in Cancer. Sulforaphane has been defined as "hormetic" dietary compound, because of its ability to induce different/opposite biological effects at different doses [199]. Treatment of mesenchymal stem cells (MSC) with low doses of sulforaphane (0.25$1 \mu \mathrm{M})$ increased cell proliferation protecting from apoptosis and senescence, and conversely higher doses (5-20 $\mu \mathrm{M})$ induced cytotoxicity together with HDAC inhibition and increasing number of apoptotic and senescent cells [199]. However, it has been frequently reported a different $\mathrm{IC}_{50}$ 
for normal and cancer cells. For example, $\mathrm{IC}_{50}$ values from 14.0 to $19.3 \mu \mathrm{M}$ were found in MCF-7, MDA-MB-231, and SK-BR-3 breast cancer cell lines, whereas the $\mathrm{IC}_{50}$ for normal human mammary epithelial cells was $81.24 \mu \mathrm{M}$ [200]. Sulforaphane-induced HDAC inhibition and induction of cell death has been shown in various cancer cells [201]. In colorectal cancer cells, sulforaphane treatment $(15 \mu \mathrm{M})$ induced alteration of histone acetylation status and a specific increase in acetylated histone $\mathrm{H} 4$ bound to the promoter region of $P 21$ leading at an increased p21Cip1/Waf1 protein expression [202]. Consistently, in vivo administration of sulforaphane inhibited HDAC activity in mouse colonic mucosa after six hours from the oral treatment with concomitant increase of acetylated $\mathrm{H} 3$ and $\mathrm{H} 4$ histone. Changes in histone acetylation status were also observed after long-term (10 weeks) administration of sulforaphane diet that resulted in augmented acetylated histones and p21 expression in the ileum, colon, prostate, and PBMC cells. Dietary sulforaphane was also able to suppress polyp formation in $A p c^{\text {min }}$ mice [203]. In addition, changes in the histone modifications of the hTERT promoter and DNA demethylation of hTERT exon 1 were observed in human breast cancer cells in response to sulforaphane [204]. Acting as HDAC inhibitor, sulforaphane may be useful in the treatment of many types of cancer in which HDAC activity and hypoacetylation contribute to malignant progression.

4.9.2. Sulforaphane as Senescence Inducer. As mentioned above, the dose and duration of sulforaphane treatment result in a divergent cell fate also in cancer cells. Sulforaphane at $5-10 \mu \mathrm{M}$ promotes cell cycle arrest, elevation in the levels of p21 and p27, and cellular senescence in breast cancer cells (MCF-7, MDA-MB-231, and SK-BR-3), whereas at the concentration of $20 \mu \mathrm{M}$, apoptosis was induced [200]. The effects were mediated by upregulation of sixty microRNAs and downregulation of thirty-two microRNAs, global hypomethylation, and decreased levels of DNA methyltransferases (DNMT1, DNMT3B), as well as nitrooxidative stress, genotoxicity, and diminished AKT signaling. Transient sulforaphane exposure for up to 6 hours induced reversible G2/M growth arrest, while exposures of 12 to 72 hours resulted in irreversible G2/M arrest and apoptosis of human colon cancer cell line [205]. Cell cycle arrest in G1 phase and induction of key effector molecules related to cellular senescence, such as p21, p27, Rb, and PAI-1, has been observed by treatment with sulforaphane of adipocytes at early stage of differentiation [206].

4.9.3. Sulforaphane as Potential Senolytic. There is currently no evidence of senolytic effects of sulforaphane.

4.9.4. Efficacy of Sulforaphane in Cancer Adjuvant Therapy. Sulforaphane is considered a good candidate in adjuvant therapy of cancer due to its proapoptotic, antiangiogenesis, and antimetastasis activities shown in preclinical settings [207]. However, clinical studies in men with recurrent prostate cancer have shown limited efficacy with significant effects only on secondary endpoints $[208,209]$.
4.10. Triptolide. Triptolide is a natural diterpenoid abundant in thunder god vine (Tripterygium wilfordii). It has gained importance because of its potential for prevention and treatment of cancer [210]. Triptolide is able to induce toxic cellular effects, which induce Nrf2 and its target genes, as it has been shown in hepatic cell lines [104].

4.10.1. Triptolide as Toxic Compound in Cancer. Triptolide $(50-100 \mathrm{nM})$ is able to decrease mitochondrial respiration and increase ROS and apoptosis in p53-deficient non-smallcell lung cancer and consequently to upregulate $\mathrm{Nrf2}$ and its target gene HO-1 and NQO1 [10]. This compound was shown to induce apoptosis and cell cycle arrest in various cancers by targeting the p53/p21 and BCL-2 pathway [211-213].

Conversely, in resistant myeloid leukemia cell lines, triptolide enhanced the sensitivity to doxorubicin-induced and imatinib-induced apoptosis through a downregulation of Nrf2 and its target genes [214].

4.10.2. Triptolide as Senescence Inducer. Triptolide has the ability to induce senescence. Treatment of liver cancer cells (HepG2) with nanomolar concentrations of triptolide (2.5$10 \mathrm{nM}$ ) induced senescence via Akt and hTERT pathway [215]. Triptolide $(3 \mathrm{nM})$ induced senescence of primary prostate adenocarcinoma cells, as demonstrated by SA- $\beta$ gal activity [216].

4.10.3. Triptolide as Potential Senolytic. There is currently no evidence of senolytic effects of triptolide. Triptolide $(0.25 \mathrm{mg} /$ $\mathrm{kg}$ i.v., twice weekly for 1,2 , and 3 months) is able to mitigate radiation-induced pulmonary fibrosis in rats [217] but conversely to senolytic drug, which can be given when fibrosis is permanent [218]; triptolide beneficial effects have been demonstrated when given before irradiation. Anyway, further studies could be performed in this area due to the important proapoptotic effects shown by triptolide in cancer cells.

4.10.4. Triptolide in Cancer Adjuvant Therapy. A phase I and pharmacological study of F60008 (a semisynthetic derivate of triptolide, which is converted to triptolide) given intravenously in patients with advanced solid tumors displayed various adverse effects without any clear proof of efficacy [219].

4.11. Allicin. Allicin, an organosulfur compound, is mainly present in garlic (Allium sativum). The compound is reported to have antimicrobial, anticancer, and cardioprotective activities [220]. Allicin inhibited lipopolysaccharideinduced vascular oxidative stress and inflammation in human umbilical vein endothelial cells, which were associated with activation of Nrf2 and reduction of TNF- $\alpha$ (tumor necrosis factor $\alpha$ ) and IL-8 (interleukin 8) production [221]. By activating Nrf2, allicin protected spinal cord tissue from traumatic injury in rats [222].

4.11.1. Allicin as Toxic Compound in Cancer. Allicin (10$30 \mu \mathrm{M})$ reduced cell viability and proliferation in several mammalian lines with higher efficacy to induce apoptosis in 3T3 and MCF-7 cell lines [223]. Treatment of liver cancer cells with allicin induced apoptotic cell death via p53 modulation [224]. 
4.11.2. Allicin as Senescence Inducer. Allicin has been shown to inhibit telomerase activity and to induce apoptosis in gastric cancer adenocarcinoma cells (SGC-7901) [225]. While conventional senescent markers have not been measured in this study, cells treated with allicin $(100 \mu \mathrm{M})$ showed typical morphological changes (enlarged and irregular) that have been reported in several models of senescence. However, cells treated with allicin underwent rapid apoptosis after morphological changes, and these changes were more likely related to cell death events rather than senescence.

4.11.3. Allicin as Potential Senolytic. Allicin has not been investigated in this area.

4.11.4. Allicin in Cancer Adjuvant Therapy. Clinical trial with allicin as adjuvant in cancer therapy is still lacking. There is a report of partial efficacy (mild increase of apoptosis in cancer tissues) of a local application of allicin, via gastroscopy ( $48 \mathrm{~h}$ before surgical intervention), in patients with progressive gastric carcinoma.

4.12. Berberine. Berberine is a naturally occurring isoquinoline alkaloid present in barberry (Berberis vulgaris), tree turmeric (B. aristata), oregon grape (B. aquifolium), goldenseal (Hydrastis canadensis), and goldethread (Coptis chinensis) [226]. Berberine has been shown to possess a wide range of pharmacological activities [227], including antidiabetic, antihyperlipidemic, antiarrhythmic, and antioxidat activities that find a common rationale in the upregulation of Nrf2-related pathways [228, 229].

4.12.1. Berberine as Toxic Compound in Cancer. Berberine displays hormetic effects "in vitro." It has been shown that berberine at low-dose range $(1.25 \sim 5 \mu \mathrm{M})$ can promote cell proliferation while at high-dose range $(10 \sim 80 \mu \mathrm{M})$ can inhibit cell proliferation [230]. In vitro treatment with berberine can inhibit cell growth and induce cell cycle arrest and apoptosis ( $\mathrm{IC}_{50}$ from 7 to $20 \mu \mathrm{M}$ ) of various cancer cells, for example, prostatic, gastrointestinal, hepatic, and mammary human cancer cells (reviewed in [231]), as well as skin- [232] and hematological-derived cancer cells [233]. Activation of AMPK, inhibition of mTOR pathway, and induction of apoptosis or autophagic cell death are the best-characterized cascade of events by which berberine exerts anticancer activity $[234,235]$.

4.12.2. Berberine as Senescence Inducer. However, there is a series of scientific evidence about the ability of berberine to exert cell type-specific effects that, in certain circumstances, include cell cycle arrest and induction of a senescent-like phenotype. Indeed, chronic treatment with berberine $(15 \mu \mathrm{M})$ for one week was shown to induce senescence in human glioblastoma cells by downregulation of EGFRMEK-ERK signaling pathway [236]. Moreover, the antitumor effects of berberine and berberine derivatives in human HER-2/neu overexpressing breast cancer cells are mediated not only by apoptotic cell death but also by increased expression of p53, p21, p16, and PAI-1 mRNAs, thus suggesting that the mechanism of action of berberine may also include the induction of CS [237]. Another potential mechanism that could explain this role of berberine in CS regards the inhibition of telomerase activity forming a G-quadruplex with telomeric DNA [238]. Finally, treatment of promyelocytic leukemia HL-60 cell line with $150 \mu \mathrm{M}$ berberine induced a time-dependent reduction in the activity of telomerase [239].

Berberine was also shown to trigger the transcriptional activity and the inhibition of the degradation of p53 in human breast cancer MCF7 cells [240]. All these observations suggest that berberine is another example of natural Nrf2-activating compound that exerts different and even contrasting, that is, gerosupressive [241] and prosenescence $[236,237]$, effects likely depending on cell type, time of exposure, and dosage. It is important to consider that most, if not all, studies in vitro with berberine tested doses in the micromolar range which is far higher than levels achievable in blood plasma after oral dosing. These observations prompt further investigation to clarify the conditions that might allow to use safely berberine in prosenescence therapy for cancer.

4.12.3. Berberine as Potential Senolytic. A compound with the ability to modulate FLIP in senescent cells may potentially be used as a senolytic drug. Berberine is among those compounds that modulates FLIP and has been included in a recent patent as potential senolytic [242]. Studies are currently in progress around this topic.

4.12.4. Berberine in Cancer Adjuvant Therapy. Recent applications related to berberine's possible therapeutic use are focused on metabolic syndrome, type 2 diabetes, and dyslipidemia. However, the use of berberine as adjuvant therapy in cancer appears to be promising as well. Berberine reduced radiation-induced lung injury (RILI) and pulmonary fibrosis in non-small-cell lung cancer (NSCLC) patients treated with radiotherapy [243]. Moreover, there is evidence that oral administration of berberine can reduce the familial adenomatous polyposis patients' polyp size [244]. Additional trial with berberine as chemopreventive agent as well as in reducing recurrence rates of colorectal adenoma (CRA) is currently ongoing.

4.13. Piperlongumine. Piperlongumine is a natural alkaloid isolated from the long pepper. It is a potent inducer of Nrf2 response and of its target genes including heme oxygenase1 (HO-1) [50]. Interestingly, HO-1 has antitumor functions in cancer cells, but cytoprotective functions in normal cells.

4.13.1. Piperlongumine as Toxic Compound in Cancer. Piperlongumine displays a high degree of selective toxicity to cancer cells. It has been identified as strong inhibitor $\left(\mathrm{IC}_{50}=1.7 \mu \mathrm{M}\right)$ of signal transducer and activator of transcription 3 (STAT3) by a recent high throughput drugrepository screening [245]. STAT3 is a validated drug target for cancer therapy and thus it is not surprising that piperlongumine was found to be able to induce apoptosis at low doses $\left(\mathrm{IC}_{50}\right.$ from 0.16 up to $5.1 \mu \mathrm{M}$ ) in multiple breast cancer cell lines having increased STAT3. This proapoptotic activity is associated with the modulation of several antiapoptotic genes including Bcl-2, BcL-xL, survivin, X-linked inhibitor of apoptosis (XIAP), and cellular inhibitor of apoptosis proteins 
(cIAP). Alone and in combination with cisplatin, piperlongumine $(2.5-15 \mu \mathrm{M})$ is able to dysregulate the oxidative stress response and kill head and neck cancer cells independently by their p53 mutational status [246] as well as a multitude of pancreatic, kidney, breast, lung, and pancreatic cell lines (Panc1, L3.6pL, A549, kidney, and SKBR3) [247]. In human oral squamous cell carcinoma, piperlongumine induces increased ROS and subsequent caspase-dependent apoptosis at $7.5-10 \mu \mathrm{M}$ [248]. However, another study found no evidence of dose-response relationship between cellular ROS, induced by piperlongumine, and its cytotoxicity [249], thus suggesting the presence of different mechanisms related to induction of cell death.

4.13.2. Piperlongumine as Senescence Inducer. Piperlongumine has been shown to suppress proliferation and to induce p21-mediated senescence $(2.5-7.5 \mu \mathrm{M})$ [248] in human oral squamous cell carcinoma cells.

4.13.3. Piperlongumine as Potential Senolytic. A recent library screening for compounds with senolytic activity identified piperlongumine as a promising compound. It has been shown to preferentially induce cell death in irradiation, replicative, and oncogene-induced senescent WI-38 fibroblasts $\left(\mathrm{EC}_{50} 6-8 \mu \mathrm{M}\right)$ compared to nonsenescent fibroblasts $\left(\mathrm{EC}_{50}\right.$ $20 \mu \mathrm{M}$ ) [46]. However, apoptotic mechanisms of piperlongumine in senescent cells were found to be independent by the generation of ROS [46].

4.13.4. Piperlongumine in Cancer Adjuvant Therapy. Piperlongumine was found to be nontoxic in mice up to a dose of $30 \mathrm{mg} / \mathrm{kg} /$ day for 14 days and caused regression of breast cancer cell line xenografts in nude mice. These results, in addition to the recently discovered activity as senolytic compound, hold promises for a potential translation in human trials.

4.14. Fisetin. Fisetin is an organic flavonoid present in numerous fruits and vegetables such as strawberries, mangoes, and cucumbers that exhibits antioxidant, neurotrophic, antiinflammatory, and anticancer effects. Attention on fisetin in the context of aging research and chemopreventive therapy is mostly related to its ability to increase transcriptional activity of Nrf2 [250] and its target gene HO-1 [251] and also to inhibit the activity of mTOR kinase [252].

4.14.1. Fisetin as Toxic Compound in Cancer. In prostate cancer cells with upregulated activity of pathway upstream mTOR, high concentration of fisetin ( $40 \mu \mathrm{M}$ and above) induces autophagic cell death [253]. Death induction in monocytic leukemia cells by fisetin $\left(\mathrm{IC}_{50}=50 \mu \mathrm{M}\right)$ was mediated by an increase in NO resulting in the inhibition of the downstream pathways of mTOR, double-strand DNA breaks, and caspase activation [254]. Fisetin can induce apoptosis and suppress the growth of colon cancer cells (HCT116 and HT29) with an IC $_{50}$ comprised from 50 to $132 \mu \mathrm{M}$ after $72 \mathrm{~h}$ of exposure [255], and similar effects were observed in prostate cancer cells (PrEC, LNCaP, and CWR22Rv1) with an $\mathrm{IC}_{50}$ comprised from 20 to $60 \mu \mathrm{M}$ after $48 \mathrm{~h}$ of exposure.
4.14.2. Fisetin as Senescence Inducer. The mechanism of accelerated cellular senescence was not observed among those involved in the antiproliferative effects of fisetin (1$50 \mu \mathrm{M})$ in PC3 or lymph node carcinoma of the prostate (LNCaP) cells [256]. There is no further investigation about a potential prosenescence effect of fisetin.

4.14.3. Fisetin as Potential Senolytic. Fisetin selectively induces apoptosis (at $5-10 \mu \mathrm{M}$ ) in senescent, but not in proliferating, HUVECs. However, it is not senolytic in senescent IMR90 fibroblasts or in primary human preadipocytes [44].

4.14.4. Fisetin in Cancer Adjuvant Therapy. Although preclinical data appear to be convincing, well-designed clinical trials in humans are needed to conclusively determine the efficacy across various cancers as well as senolytic adjuvant therapy.

4.15. Phloretin. Phloretin is a dihydrochalcone flavonoid, which can be found in apple tree leaves. Phloretin has been shown to protect hepatocytes against oxidative stress [58] as well as HEI-OC1 auditory cells against cisplatin-induced apoptosis [51] by upregulating Nrf2 defensive pathway. Importantly, the cytoprotective effects of phloretin were also observed at relatively low doses $(2.5-5 \mu \mathrm{M})$ also in $\mathrm{H} 9 \mathrm{c} 2$ cardiomyoblasts exposed to arsenic trioxide, a drug used in the treatment of acute promyelocytic leukemia that is associated to cardiotoxic side effects [257].

4.15.1. Phloretin as Toxic Compound in Cancer. Phloretin is known to inhibit glucose transporter (GLUT) 2, a process which results in the induction of apoptosis in cells with high metabolic requirement, as shown in human liver cancer cells HepG2 treated with $200 \mu \mathrm{M}$ phloretin [258]. At the dose of $10 \mathrm{mg} / \mathrm{kg}$, phloretin was found to exert antitumor effects in immune deficiency mice carrying a HepG2 xenograft [258].

Moreover, phloretin was shown to induce apoptosis of non-small-cell lung cancer (NSCLC) cell line A549, Calu-1, $\mathrm{H} 838$, and $\mathrm{H} 520$ ( $\mathrm{IC}_{50}$ approx. from 50 to $100 \mu \mathrm{M}$ ) through deregulation of Bcl-2 [259] and other ROS-related pathways, such as P38 MAPK and JNK1/2 [260] which are related to the rise of ROS. Interestingly, the anticancer effects were enhanced in presence of cisplatin, which suggest a potential in adjuvant cancer therapy. Similar proapoptotic effects, associated with increased ROS and ROS-related pathways, were observed after treatment with very high $(200-300 \mu \mathrm{M})$ concentrations of phloretin [261].

4.15.2. Phloretin as Senescence Inducer. While there is evidence that phloretin can induce cell cycle arrest in cancer cells [261], this process seems to be unrelated to senescence induction as there are no clear data about the possibility to induce senescence with phloretin.

4.15.3. Phloretin as Potential Senolytic. Phloretin at $50 \mu \mathrm{M}$ was found to specifically reduce the viability of therapyinduced senescent lymphoma cells [45]. These cells were also shown to be sensitive to another blocker of glucose transporters, cytochalasin B, thus suggesting that the mechanism 
by which phloretin induces cell death in senescent cells is related to their increased metabolic requirement.

4.15.4. Phloretin in Cancer Adjuvant Therapy. The recent observation related to the senolytic activity of phloretin as well as its potential in combination with withaferin $\mathrm{A}$ to suppress gefitinib-resistant adenocarcinoma cell line growth [262] appears to be promising therapeutic strategy to overcome the occurrence of cancer relapse and the resistance to chemotherapy. However, these senescent and glucosetargeting therapeutic strategies have still not been tested in clinical settings.

\section{Mechanisms Mediating the Cytoprotective, Cytotoxic, or Prosenescence Effects of Nrf2- Activating Compounds}

Activation of Nrf2-regulated cytoprotective response could provide a selective advantage to tumor cells which is clearly in contrast to the majority of effects described in the above chapters. In line with the hypothesis that Nrf2 response is an advantage for cancer cells, some types of polyphenols (usually belonging to the flavone class) have been shown to sensitize different cancer cells to chemotherapy via an inhibitory activity on Nrf2 signaling pathway. These compounds include luteolin [263], chrysin [264], and apigenin [265] which, in turn, was shown to induce senescence in IMR-90 cells [266]. These results might form a good rationale to use these compounds as adjuvant in cancer therapy. However, a multitude of data, exposed in the chapters above, supports the opposite concept that most polyphenols and other natural bioactive compounds activating the Nrf2 pathway can display cytotoxic effects or promote senescence in cancer cells. This dichotomy could be explained by the activity of pathways unrelated to Nrf2. Moreover, tissue and cell type specificity of Nrf2 downstream targets appear to be still poorly understood and the range of stress-response phenotypes observed when components of the pathway are genetically disrupted in mice is not completely explained. Keap1 $\mathrm{KO}$ mice hepatocytes experience a different signaling and gene expression compared with controls treated with an Nrf2-inducing agent [267]. Some of the induced factors can even antagonize Nrf2 thus suggesting that in the presence of unrepaired damage, such as in cancer cells, the complex response to Nrf2 includes damage-sensing factors that may activate apoptotic or senescence mechanisms. Cytoprotective effects of $\mathrm{Nrf} 2$ against oxidative stress are related to the presence of a functional aryl hydrocarbon receptor (AhR), a transcription factor that display pleiotropic activity in the context of carcinogenesis [13] and while some AhR ligands can suppress senescence acting as tumor promoters [268], recent work suggests that Ahr gene can function as a tumor suppressor gene by inhibiting cell proliferation and promoting senescent-like phenotype thus counteracting cancer progression [269-271]. Bidirectional interactions of Nrf2 and AhR have been reported, thus suggesting that Nrf2 can directly modulate AhR signaling [272]. This signaling network includes Cyp1A1 and Cyp1B1 that have been reported to induce upregulation of the cyclin-dependent kinase inhibitors p27 and p21 [273] that are regarded as key effectors of cellular senescence.

Another interaction of Nrf2 that deserves attention in the context of cellular senescence regards p53. The transcription of some Nrf2 target genes involved in the antioxidant response can be suppressed by p53 [274], but their mutual interaction still remains unclear. It has been reported the Nrf2 can increase the expression of the p53 inhibitor mouse double minute 2 homolog (MDM2), which is an AREregulated target gene [275]. However, p53 can be stabilized by Nrf2 target genes, that is, NQO1, suggesting both a positive and negative coregulation between p53 and Nrf2 [274] that is likely affected by the specific genomic and epigenomic profile of the target cell as well as by the duration of the stress. Epigenetic changes induced by natural compounds targeting Nrf2 could be likely involved in this process. For example, EGCG, a known Nrf2-activating polyphenol, can reduce the expression of miRNAs that target and suppress p53 [276], while epigenetic depression of one of these miRNAs (miR200a) was reported to contribute to the dysregulation of Nrf2 activity in breast cancer [277].

Nrf2 can also interact downstream of p53 with its target gene p21 [64] or with p16 pathway by activating Notch-1 signaling. One or more functional ARE sequences exist in the promoter of Notch1, thus it is not surprising that Notch1 signaling can be triggered by Nrf2 [14]. Interestingly, Notch1 may act as an oncogene or a tumor suppressor gene even within the same tumor type, and recently, it has been implicated in induction of cellular senescence mediated by p16 [278] and p21 [279].

Finally, the Jun dimerization protein 2 (JDP2), an important player in the senescence program [280], has a critical role as a cofactor for Nrf2 in the regulation of the antioxidantresponsive genes and production of ROS [281].

These data point towards a possible extension of Nrf2 to a more complex response that include damage-sensing prosenescence pathways, likely activated with a different timing in the case of persistent damage (Figure 2). However, it is also important to consider the multitarget ability of natural compounds, which might be able to interfere with senescence or apoptosis-related pathways, usually not directly related to Nrf2. These include multiple targets that have been frequently observed to be altered in cancer and senescent cells and that form the rationale to explain the different response from normal cells to the studied compounds [5]. Among the most critical targets that are noteworthy to mention are as follows:

(a) The reprogrammed metabolic pathway in cancer (Warburg effect or aerobic glycolysis) and some therapy-induced senescent cells, consisting in the switch of normal metabolism to support proliferation of cancer cells or production of SASP in senescent cells targeting glycolytic and other metabolic pathways, makes some cancer [282] and senescent cells [45] more susceptible to cell death than normal cells

(b) The defects in checkpoint kinases and repair genes that make cancer cells more susceptible to cell death following HDAC inhibition [104] 


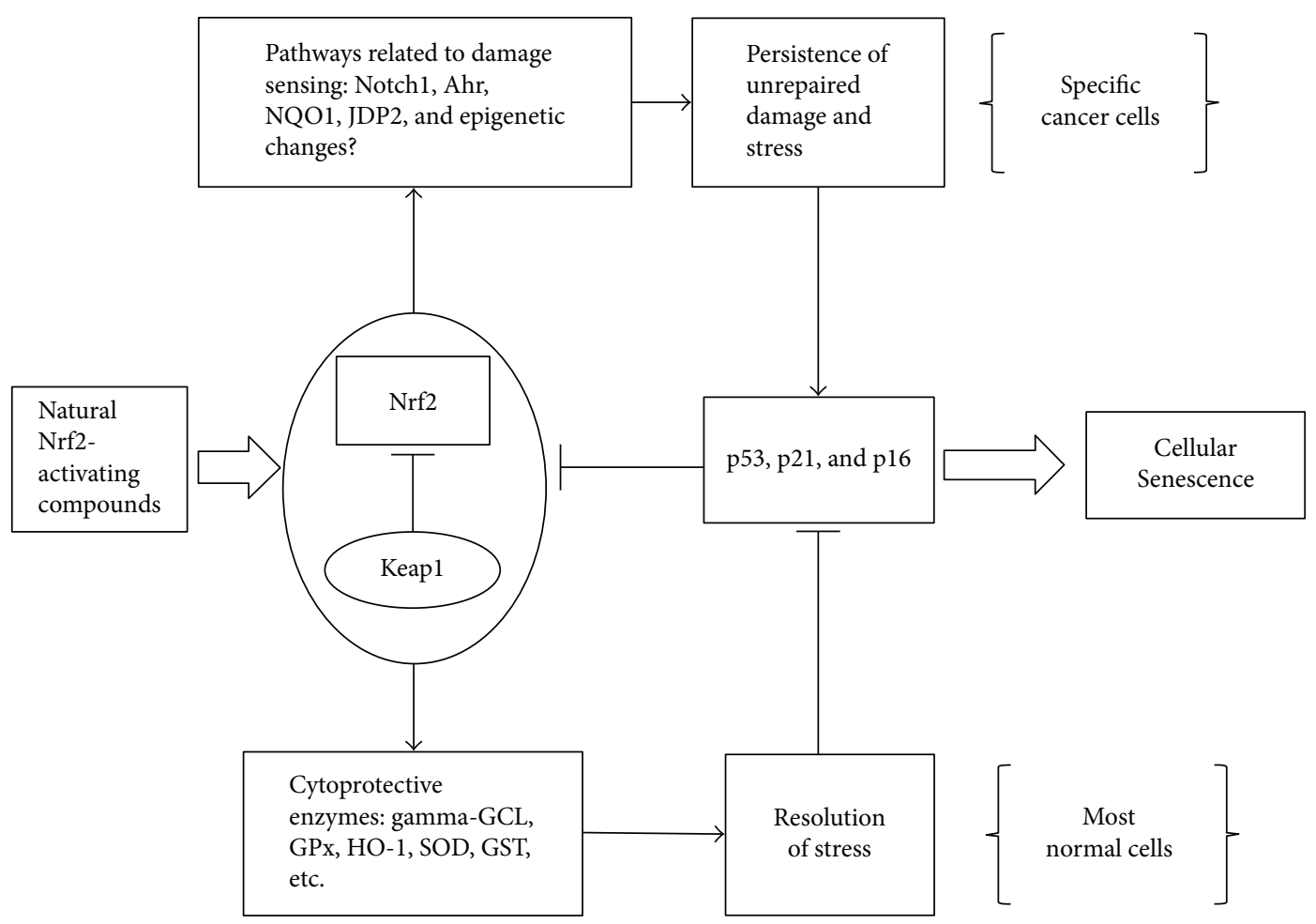

FIGURE 2: Potential mechanisms leading to senescence by NRF2-activating compounds in cancer cells. The response under NRF2 signaling involve the activation of glutamylcysteine ligase ( $\gamma$-GCL), glutathione peroxidase (GPx), heme oxygenase 1 (HO-1), superoxide dismutase (SOD), glutathione S-transferase (GST), and many other enzymes involved in the antioxidant cytoprotective response that lead to suppression of senescence-related pathways (i.e., p53, p21, and p16). However, this response include and interact with additional genes, such as Notch-1, NADPH-quinone oxidoreductase (NQO1), the aryl hydrocarbon receptor (AhR), the Jun dimerization protein 2 (JDP2), and perhaps epigenetic changes that may be involved in sensing stress and damage and that are known to participate in processes leading to cellular senescence. In the case of (particular) cancer cells, the persistence of unresolved damage can eventually lead these pathways to the reactivation of the senescence program.

(c) The upregulation of antiapoptotic factors including $\mathrm{Bcl}-2 / \mathrm{Bcl}-\mathrm{xL}$ and others mentioned above (shared by some cancer and senescent cells) which makes these cells susceptible to selective inhibitor

(d) The inhibition of autophagy (as consequence of high PI3K/Akt/mTor signaling) that makes cancer cells susceptible to cell death by AMPK inhibitors and starvation [283]

(e) The upregulation of both ROS and stress response pathway in cancer cells which make them susceptible to cytostasis by antioxidant treatment (due to unbalanced stress response) [284]

\section{Nrf2-Activating Compounds and the Clearance of Senescent Cells}

Senescent cells are an important source of inflammatory factors (SASP-related factors) for tumor progression [19] and can promote the development of cancer in the surrounding environment. In certain cases, it has been hypothesized that senescent cancer cells might even be able to overcome the "permanent" cell cycle arrest, revert their phenotype, and restart proliferation, thus suggesting that senescence may be used as therapy escape system by some cancer cells [16]. Taking into account that senescent cells can display long-term survival and resistance to apoptosis [285], finding ways to eliminate senescent cells might deserve a great impact on future adjuvant therapeutic strategies against cancer. This kind of senolytic adjuvant therapy could be important to reduce the incidence of relapses and the adverse effects of the therapy, as recently demonstrated in animal models [42]. In the last five years, at least 12 compounds have been identified as agents with senolytic activity in vitro, and more than half of them have been shown to be effective in vivo in animal models. Four of these candidate senolytics are natural bioactive compounds that have been described in the chapters above, namely, fisetin, quercetin, piperlongumine, and phloretin, and the estimation of their $\mathrm{IC}_{50}$ for senescent and nonsenescent cells is described in Table 1. The finding that some natural compounds that can be found in fruit and vegetables have been found to reduce specifically the viability of senescent cells is remarkable. Apparently, this could improve and accelerate the translation of these findings into clinical trials, as these compounds are available as supplement or included in extracts that are commercially available. However, there are some limitations that deserve to be discussed. First of all, it is important to bear in mind that a 





natural compound is not necessarily less toxic than a synthetic compound, especially when the doses required to achieve a therapeutic efficacy are high. If we look at the estimated $\mathrm{IC}_{50}$ reported in Table 1, it appears that the differences between the $\mathrm{IC}_{50}$ of nonsenescent and senescent cells are comprised in a relatively narrow range and that their ratio is comprised from 2 to 3 . This means that at high dosage, these compounds could be toxic also for normal cells especially assuming a nonuniform distribution through the body. Moreover, experiments in vitro cannot take into account the effects of multitude of metabolites that originates from a bioactive compound as a consequence of the microflora and the enzymatic activity of our body. In the case these compounds should be used as senolytics, the therapeutic regimen would consist of a single or few more treatments with very high doses. In the case of quercetin, there is no example of senolytic therapy given alone, but its combination with dasatinib has been tested in mice. The combination of dasatinib $5 \mathrm{mg} / \mathrm{Kg}$ and quercetin $50 \mathrm{mg} / \mathrm{Kg}$ has been given as weekly single dose (by gavage) in ERRC1 ${ }^{-/ \Delta}$ mice for several weeks [38] as well as in the form of single monthly dose (dasatinib $5 \mathrm{mg} / \mathrm{Kg}$ and quercetin $10 \mathrm{mg} / \mathrm{Kg}$ ) for 3 months in normal mice [39] with several reported benefits and without any report of side effects. A similar dose in humans would approximately correspond to a dose around $1.5-2 \mathrm{~g}$, while common oral dosage of quercetin supplements is in the range 50-500 mg. Moreover, when $2 \mathrm{~g}$ /day (corresponding to 25 and $36 \mathrm{mg} / \mathrm{Kg}$ for individuals of 80 and $55 \mathrm{Kg}$ body weight, resp.) was given to healthy men, the serum quercetin concentration was found to be $5 \mu \mathrm{M}$ [286], which is below the $\mathrm{IC}_{50}$ observed for senescent cells in vitro Table 1 . In addition, the efficacy of quercetin as senolytic has been proven only in irradiation-induced senescent HUVEC while there is no evidence of this activity for any other model of senescence.

Also, fisetin displays a restricted activity that is limited to irradiation-induced senescent HUVEC at concentration higher than those reported for quercetin. If the $\mathrm{IC}_{50}$ of fisetin in vitro is 3-fold, those described for quercetin, we should expect senolytic doses that are very near to a toxic dosage. In mice, the $\mathrm{LD}_{50}$ dose was $180 \mathrm{mg} / \mathrm{Kg}$ given intravenously, which may suggest that doses above $500 \mathrm{mg}$ in humans may be unsafe. For piperlongumine and phloretin, there is not a clear $\mathrm{LD}_{50}$. However, piperlongumine displays senolytic activity at concentration below $10 \mu \mathrm{M}$ in vitro which may suggest a potential to achieve these concentrations in vivo.

Anyway, at this moment, it is unclear if bioactive natural compounds can be safely used as adjuvant senolytic agents after cancer therapy. Moreover, it is unclear why it should be preferred a natural compound to a peptide (FOXO4DRI) or a drug (Navitoclax) that have a substantially higher ratio between the respective $\mathrm{IC}_{50}$ of nonsenescent to senescent cells $[43,287]$ and thus are more likely, at least theoretically, to display less side effects at senolytic doses.

\section{Concluding Remarks}

CS likely evolved as a tumor-suppressing mechanism to prevent proliferation of cells that are at risk for acquiring potentially hazardous and transforming mutations. The possibility that putative cytoprotective natural compounds can reactivate pathways that induce apoptosis or senescence in cancer cells or that display senolytic activity appears a realistic perspective in vitro and a promising field of research. Emerging evidence has demonstrated that therapy-induced senescence can be achieved at much lower doses of chemotherapy and that it is a critical mechanism through which many anticancer agents inhibit the growth of tumor cells [288]. However, there are still lots of problems that need to be addressed in planning clinical trials. The first question that needs to be addressed is can we efficiently use adjuvant natural compounds to reduce the dose of chemotherapy while keeping the same efficacy and/or reducing undesired side effects associated with the therapy. The most likely answer is that it may depend on the cancer type and on the therapy scheme. In clear antagonism with excellent in vitro findings, most clinical trials performed up to now show extremely limited efficacy of any adjuvant therapy with these bioactive compounds (Table 2). There is already some (but limited) evidence that adjustments in the therapy scheme, especially in the case of curcumin, might help to achieve promising results. However, most applications are directed to elucidate the safety and bioavailability of the compound in oncologic patients. Even though a close correlation with the induction of CS has not been directly highlighted, some biological effects have been demonstrated as a direct effect of curcumin treatment.

In spite of these promises, we should acknowledge that now the benefit of the use of nutraceuticals as adjuvant in cancer therapies seems to be limited by a number of factors. These include issues related to the effective bioavailability of such active compound (in safety condition of treatment) but also concerning the heterogeneity of the population cohort in terms of age, type of cancer, comorbidity, and schedule of treatment. There are always concerns that the concentrations frequently used in vitro are excessive (tens to thousands of micromolar) and may not therefore reflect what happens with more physiological exposures (nanomolar ranges). For example, even if most of published studies in cell culture systems used 10-100 $\mu \mathrm{M}$ of EGCG [5], the blood level of EGCG after consumption of 2-3 cups of green tea was reported to be $0.1-0.6 \mu \mathrm{M}$ [116]. Similarly, for berberine, in spite of the use of micromolar ranges in cell culture, the $\mathrm{C}$ max in humans after an oral dose of $400 \mathrm{mg}$ was reported to be $0.1 \mathrm{nM}$ [289], while higher doses (above $0.9 \mathrm{~g} /$ day) were shown to induce gastrointestinal side effects (Table 2). Moreover, the oxygen partial pressure in a cell culture system is much higher than that in the blood or tissues and the metabolism that occurs after (a limited) intestinal absorption suggests that the real "actors" are likely to be metabolites rather than the original compound tested in cell culture. Last, but not least, the possibility that these Nrf2activating compounds can promote an antioxidant cytoprotective response in cancer cells thus aggravating resistance to chemotherapy should not be under evaluated. This problem could be afforded with more studies around the complex response of Nrf2 pathways in presence of cancer-specific alterations so that a personalized strategy can be developed. Moreover, induction of CS does not ensure that these cells 


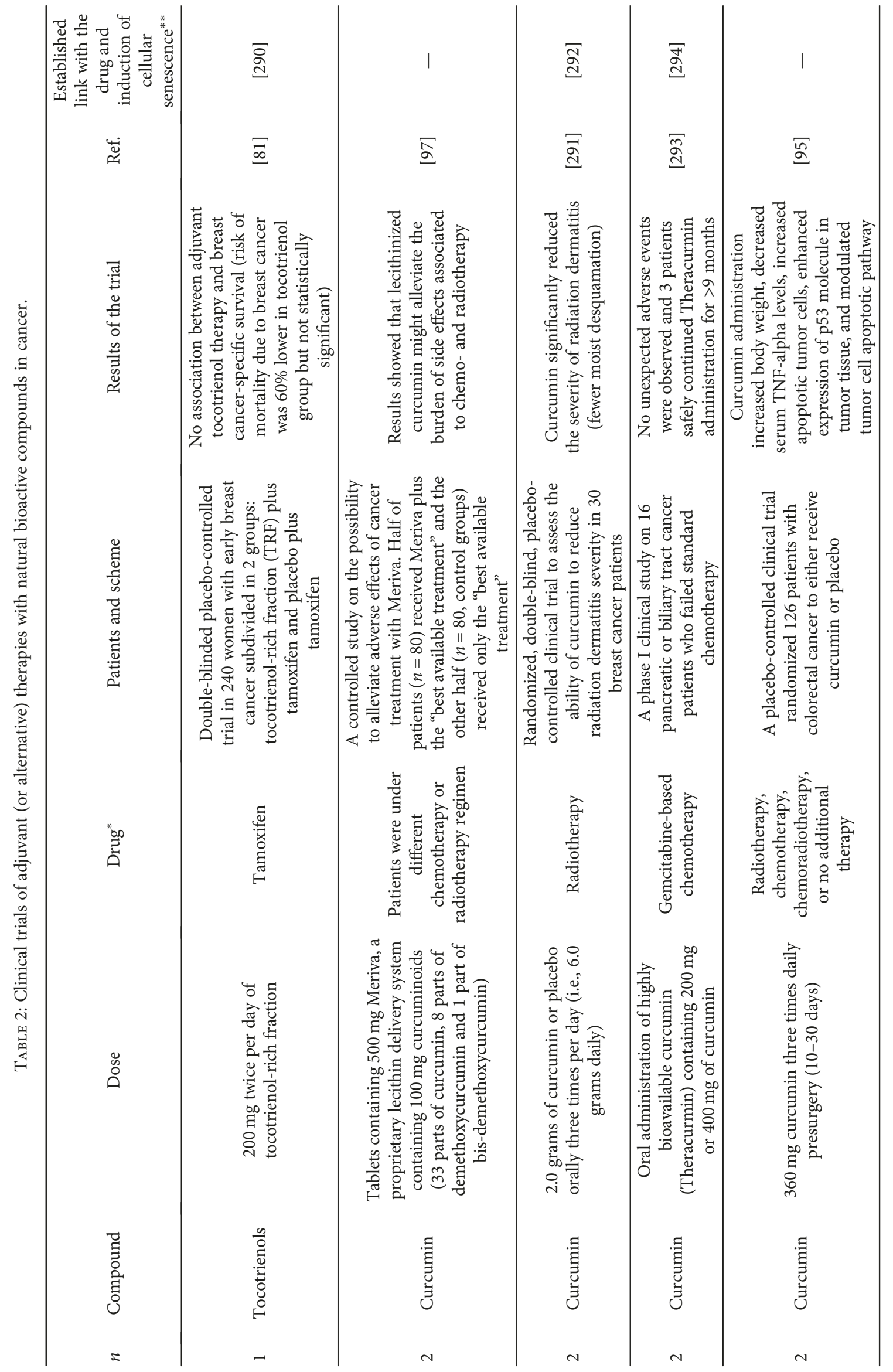









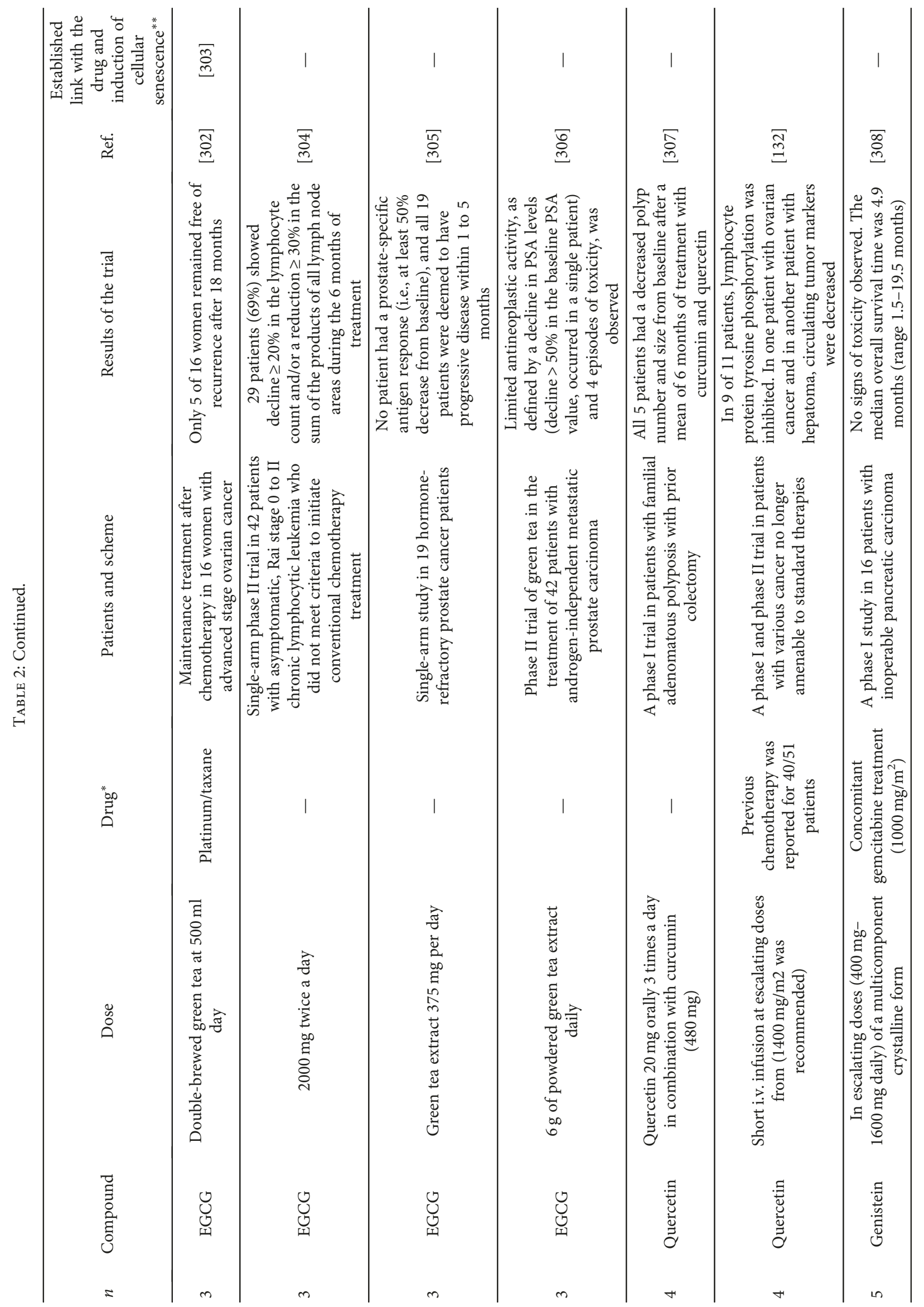









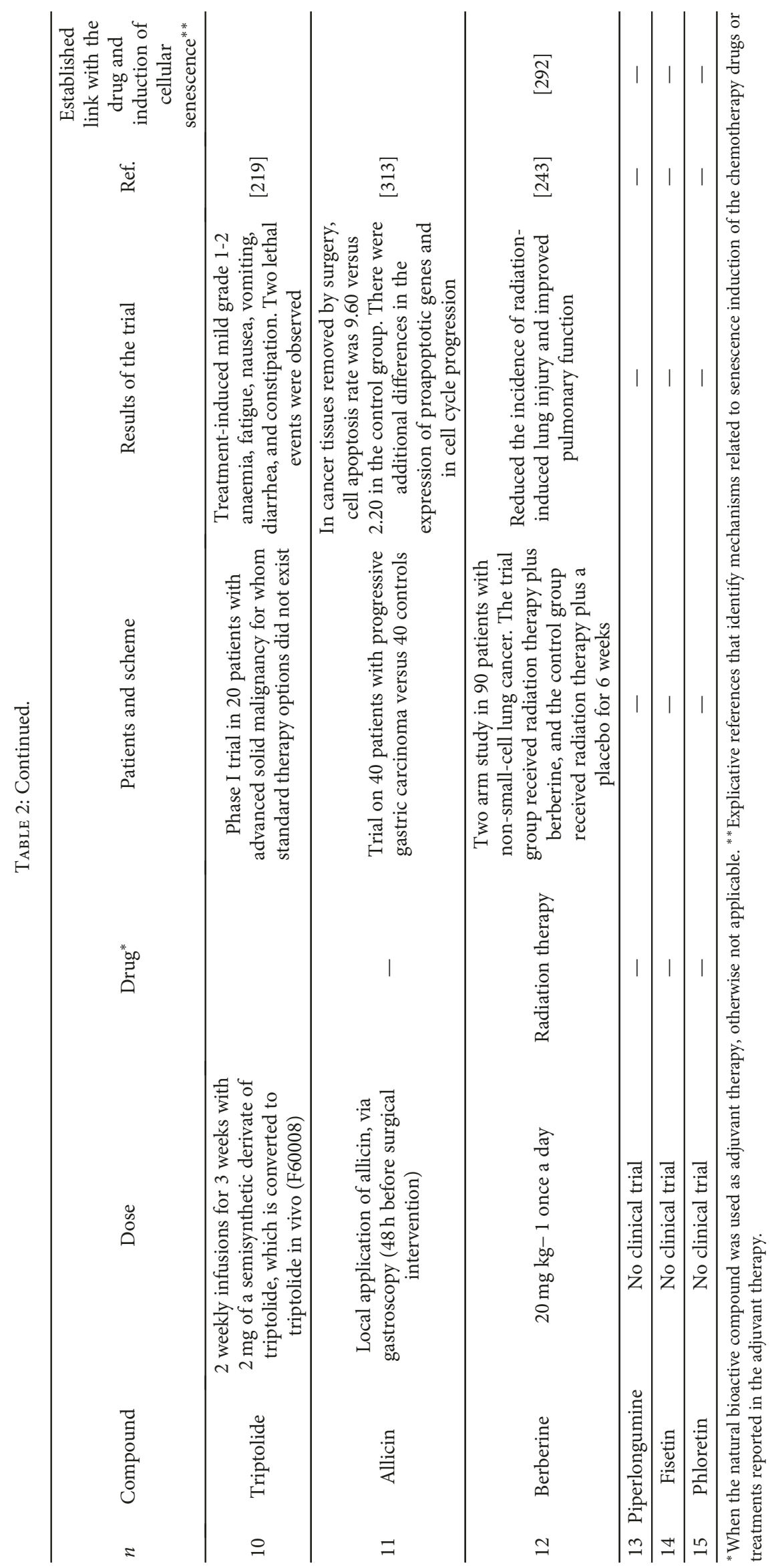


can be cleared off by the immune system and they might eventually use senescence as a system to escape death with the potential to revert their phenotype later in time. This problem might be potentially avoided with the recent development of senolytics, which include quercetin, fisetin, piperlongumine, and phloretin among natural bioactive compounds. These senolytics may be useful in the case cancer cells may use senescence as an escape strategy from therapy as well as to reduce side effects of therapy. Studies on senolytic compounds open the feasibility of a new therapeutic scheme with a single dose of the compound after radio- or chemotherapy without the needs for escalation doses and continuous treatments (Figure 1). Overall, combining therapies with natural compounds with the aims not only to induce senescence in cancer cells but also to clear off from the organism senescent cells appear as a promising strategy in this field.

\section{Conflicts of Interest}

The authors declare that they have no conflicts of interest.

\section{Acknowledgments}

The study has been partially funded through the revenues of the " 5 per Mille" donations received by INRCA through the Italian Ministry of Health.

\section{References}

[1] J. Campisi and F. d'Adda di Fagagna, "Cellular senescence: when bad things happen to good cells," Nature Reviews Molecular Cell Biology, vol. 8, no. 9, pp. 729-740, 2007.

[2] D. Muñoz-Espín and M. Serrano, "Cellular senescence: from physiology to pathology," Nature Reviews Molecular Cell Biology, vol. 15, no. 7, pp. 482-496, 2014.

[3] T. Tchkonia, Y. Zhu, J. van Deursen, J. Campisi, and J. L. Kirkland, "Cellular senescence and the senescent secretory phenotype: therapeutic opportunities," The Journal of Clinical Investigation, vol. 123, no. 3, pp. 966-972, 2013.

[4] M. Provinciali, M. Cardelli, F. Marchegiani, and E. Pierpaoli, "Impact of cellular senescence in aging and cancer," Current Pharmaceutical Design, vol. 19, no. 9, pp. 1699-1709, 2013.

[5] M. Malavolta, L. Costarelli, R. Giacconi et al., "Modulators of cellular senescence: mechanisms, promises, and challenges from in vitro studies with dietary bioactive compounds," Nutrition Research, vol. 34, no. 12, pp. 1017-1035, 2014.

[6] M. Provinciali, E. Pierpaoli, F. Piacenza et al., "Chapter 22-nutritional modulators of cellular senescence in vitro," in Molecular Basis of Nutrition and Aging, M. Malavolta and E. Mocchegiani, Eds., pp. 293-312, Elsevier Academic Press, London, UK, 2016.

[7] G. Costa, V. Francisco, M. C. Lopes, M. T. Cruz, and M. T. Batista, "Intracellular signaling pathways modulated by phenolic compounds: application for new anti-inflammatory drugs discovery," Current Medicinal Chemistry, vol. 19, no. 18, pp. 2876-2900, 2012.

[8] A. Giudice, C. Arra, and M. C. Turco, "Review of molecular mechanisms involved in the activation of the Nrf2-ARE signaling pathway by chemopreventive agents," Methods in Molecular Biology, vol. 647, pp. 37-74, 2010.
[9] K. C. Wu, P. R. McDonald, J. Liu, and C. D. Klaassen, "Screening of natural compounds as activators of the keap1nrf2 pathway," Planta Medica, vol. 80, no. 1, pp. 97-104, 2014.

[10] A. Kumar, C. Corey, I. Scott, S. Shiva, and J. D'Cunha, "Minnelide/Triptolide impairs mitochondrial function by regulating SIRT3 in P53-dependent manner in non-small cell lung cancer," PLoS One, vol. 11, no. 8, article e0160783, 2016.

[11] R. Sarkar, S. Mukherjee, J. Biswas, and M. Roy, "Phenethyl isothiocyanate, by virtue of its antioxidant activity, inhibits invasiveness and metastatic potential of breast cancer cells: HIF- $1 \alpha$ as a putative target," Free Radical Research, vol. 50, no. 1, pp. 84-100, 2016.

[12] P. Su, J. Zhang, S. Wang et al., "Genistein alleviates leadinduced neurotoxicity in vitro and in vivo: involvement of multiple signaling pathways," Neurotoxicology, vol. 53, pp. 153-164, 2016.

[13] E. Kansanen, S. M. Kuosmanen, H. Leinonen, and A.-L. Levonen, "The Keap1-Nrf2 pathway: mechanisms of activation and dysregulation in cancer," Redox Biology, vol. 1, no. 1, pp. 45-49, 2013.

[14] N. Wakabayashi, S. L. Slocum, J. J. Skoko, S. Shin, and T. W. Kensler, "When NRF2 talks, who's listening?," Antioxidants \& Redox Signaling, vol. 13, no. 11, pp. 1649-1663, 2010.

[15] E. Pierpaoli, V. Viola, A. Barucca, F. Orlando, F. Galli, and M. Provinciali, "Effect of annatto-tocotrienols supplementation on the development of mammary tumors in HER-2/ neu transgenic mice," Carcinogenesis, vol. 34, no. 6, pp. 1352-1360, 2013.

[16] R. R. Gordon and P. S. Nelson, "Cellular senescence and cancer chemotherapy resistance," Drug Resistance Updates, vol. 15, no. 1-2, pp. 123-131, 2012.

[17] L. Hoenicke and L. Zender, "Immune surveillance of senescent cells-biological significance in cancer- and non-cancer pathologies," Carcinogenesis, vol. 33, pp. 1123-1126, 2012.

[18] J. Sage, A. L. Miller, P. A. Pérez-Mancera, J. M. Wysocki, and T. Jacks, "Acute mutation of retinoblastoma gene function is sufficient for cell cycle re-entry," Nature, vol. 424, no. 6945, pp. 223-228, 2003.

[19] A. R. Davalos, J.-P. Coppe, J. Campisi, and P.-Y. Desprez, "Senescent cells as a source of inflammatory factors for tumor progression," Cancer and Metastasis Reviews, vol. 29, no. 2, pp. 273-283, 2010.

[20] O. H. Jeon, C. Kim, R.-M. Laberge et al., "Local clearance of senescent cells attenuates the development of posttraumatic osteoarthritis and creates a pro-regenerative environment," Nature Medicine, vol. 23, no. 6, pp. 775-781, 2017.

[21] B. Bernardes de Jesus and M. A. Blasco, "Assessing cell and organ senescence biomarkers," Circulation Research, vol. 111, no. 1, pp. 97-109, 2012.

[22] W. Wagner, "Senescence is heterogeneous in mesenchymal stromal cells: kaleidoscopes for cellular aging," Cell Cycle, vol. 9, no. 15, pp. 2923-2924, 2010.

[23] C. D. Wiley, J. M. Flynn, C. Morrissey et al., “Analysis of individual cells identifies cell-to-cell variability following induction of cellular senescence," Aging Cell, vol. 16, no. 5, pp. 1043-1050, 2017.

[24] J. Campisi, “Aging, cellular senescence, and cancer," Annual Review of Physiology, vol. 75, no. 1, pp. 685-705, 2013. 
[25] J. M. van Deursen, "The role of senescent cells in ageing," Nature, vol. 509, no. 7501, pp. 439-446, 2014.

[26] C. López-Otín, M. A. Blasco, L. Partridge, M. Serrano, and G. Kroemer, "The hallmarks of aging," Cell, vol. 153, no. 6, pp. 1194-1217, 2013.

[27] J. Krishnamurthy, C. Torrice, M. R. Ramsey et al., "Ink4a/Arf expression is a biomarker of aging," The Journal Clinical Investigation, vol. 114, no. 9, pp. 1299-1307, 2004.

[28] M. Collado, M. A. Blasco, and M. Serrano, "Cellular senescence in cancer and aging," Cell, vol. 130, no. 2, pp. 223233, 2007.

[29] M. V. Blagosklonny, "Hypoxia, MTOR and autophagy," Autophagy, vol. 9, no. 2, pp. 260-262, 2013.

[30] J.-P. Coppé, P.-Y. Desprez, A. Krtolica, and J. Campisi, “The senescence-associated secretory phenotype: the dark side of tumor suppression," Annual Review of Pathology, vol. 5, no. 1, pp. 99-118, 2010.

[31] J.-P. Coppé, C. K. Patil, F. Rodier et al., "Senescence-associated secretory phenotypes reveal cell-nonautonomous functions of oncogenic RAS and the p53 tumor suppressor," PLoS Biology, vol. 6, no. 12, pp. 2853-2868, 2008.

[32] J. C. Acosta, A. Banito, T. Wuestefeld et al., "A complex secretory program orchestrated by the inflammasome controls paracrine senescence," Nature Cell Biology, vol. 15, no. 8, pp. 978-990, 2013.

[33] M. Malavolta, L. Costarelli, R. Giacconi et al., "Changes in $\mathrm{Zn}$ homeostasis during long term culture of primary endothelial cells and effects of Zn on endothelial cell senescence," Experimental Gerontology, vol. 99, pp. 35-45, 2017.

[34] B. Hampel, M. Wagner, D. Teis, W. Zwerschke, L. A. Huber, and P. Jansen-Durr, "Apoptosis resistance of senescent human fibroblasts is correlated with the absence of nuclear IGFBP-3," Aging Cell, vol. 4, no. 6, pp. 325-330, 2005.

[35] D. J. Baker, T. Wijshake, T. Tchkonia et al., "Clearance of p16 ${ }^{\text {Ink4a }}$-positive senescent cells delays ageing-associated disorders," Nature, vol. 479, pp. 232-236, 2011.

[36] M. Demaria, "Senescent cells: new target for an old treatment?" Molecular \& Cellular Oncology, vol. 4, no. 3, article e1299666, 2017.

[37] J. L. Kirkland, T. Tchkonia, Y. Zhu, L. J. Niedernhofer, and P. D. Robbins, "The clinical potential of senolytic drugs," Journal of the American Geriatrics Society, vol. 65, no. 10, pp. 2297-2301, 2017.

[38] Y. Zhu, T. Tchkonia, T. Pirtskhalava et al., "The Achilles' heel of senescent cells: from transcriptome to senolytic drugs," Aging Cell, vol. 14, no. 4, pp. 644-658, 2015.

[39] C. M. Roos, B. Zhang, A. K. Palmer et al., "Chronic senolytic treatment alleviates established vasomotor dysfunction in aged or atherosclerotic mice," Aging Cell, vol. 15, no. 5, pp. 973-977, 2016.

[40] M. J. Schafer, T. A. White, K. Iijima et al., "Cellular senescence mediates fibrotic pulmonary disease," Nature Communications, vol. 8, article 14532, 2017.

[41] H. Fuhrmann-Stroissnigg, Y. Y. Ling, J. Zhao et al., "Identification of HSP90 inhibitors as a novel class of senolytics," Nature Communications, vol. 8, no. 1, article 422, 2017.

[42] M. Demaria, M. N. O’Leary, J. Chang et al., "Cellular senescence promotes adverse effects of chemotherapy and cancer relapse," Cancer Discovery, vol. 7, no. 2, pp. 165-176, 2017.

[43] M. P. Baar, R. M. C. Brandt, D. A. Putavet et al., "Targeted apoptosis of senescent cells restores tissue homeostasis in response to chemotoxicity and aging," Cell, vol. 169, no. 1, pp. 132-147.e16, 2017.

[44] Y. Zhu, E. J. Doornebal, T. Pirtskhalava et al., "New agents that target senescent cells: the flavone, fisetin, and the BCL-XL inhibitors, A1331852 and A1155463," Aging, vol. 9, pp. 955-963, 2017.

[45] J. R. Dörr, Y. Yu, M. Milanovic et al., "Synthetic lethal metabolic targeting of cellular senescence in cancer therapy," Nature, vol. 501, no. 7467, pp. 421-425, 2013.

[46] Y. Wang, J. Chang, X. Liu et al., "Discovery of piperlongumine as a potential novel lead for the development of senolytic agents," Aging, vol. 8, no. 11, pp. 2915-2926, 2016.

[47] M. Malavolta, E. Pierpaoli, R. Giacconi et al., "Pleiotropic effects of tocotrienols and quercetin on cellular senescence: introducing the perspective of senolytic effects of phytochemicals," Current Drug Targets, vol. 17, no. 4, pp. 447459, 2016.

[48] A. Murakami, H. Ashida, and J. Terao, "Multitargeted cancer prevention by quercetin," Cancer Letters, vol. 269, no. 2, pp. 315-325, 2008.

[49] S. Kim, K. J. Choi, S.-J. Cho et al., "Fisetin stimulates autophagic degradation of phosphorylated tau via the activation of TFEB and Nrf2 transcription factors," Scientific Reports, vol. 6, no. 1, article 24933, 2016.

[50] H.-N. Lee, H.-O. Jin, J.-A. Park et al., "Heme oxygenase-1 determines the differential response of breast cancer and normal cells to Piperlongumine," Molecules and Cells, vol. 38, no. 4, pp. 327-335, 2015.

[51] B.-M. Choi, X. Y. Chen, S. S. Gao, R. Zhu, and B. R. Kim, "Anti-apoptotic effect of phloretin on cisplatin-induced apoptosis in HEI-OC1 auditory cells," Pharmacological Reports, vol. 63, no. 3, pp. 708-716, 2011.

[52] A. Juknat, M. Pietr, E. Kozela et al., "Differential transcriptional profiles mediated by exposure to the cannabinoids cannabidiol and $\Delta^{9}$-tetrahydrocannabinol in BV-2 microglial cells," British Journal of Pharmacology, vol. 165, no. 8, pp. 2512-2528, 2012.

[53] R. Kannappan, S. C. Gupta, J. H. Kim, and B. B. Aggarwal, "Tocotrienols fight cancer by targeting multiple cell signaling pathways," Genes \& Nutrition, vol. 7, no. 1, pp. 43-52, 2012.

[54] H. M. Leinonen, E. Kansanen, P. Pölönen, M. Heinäniemi, and A. L. Levonen, "Dysregulation of the Keap1-Nrf2 pathway in cancer," Biochemical Society Transactions, vol. 43, no. 4, pp. 645-649, 2015.

[55] D. Volonte, Z. Liu, P. M. Musille et al., "Inhibition of nuclear factor-erythroid 2-related factor (Nrf2) by caveolin-1 promotes stress-induced premature senescence," Molecular Biology of the Cell, vol. 24, pp. 1852-1862, 2013.

[56] L. Hecker, N. J. Logsdon, D. Kurundkar et al., "Reversal of persistent fibrosis in aging by targeting Nox4-Nrf2 redox imbalance," Science Translational Medicine, vol. 6, no. 231, article 231ra47, 2014.

[57] G. Yang, K. Zhao, Y. Ju et al., "Hydrogen sulfide protects against cellular senescence via S-sulfhydration of Keap1 and activation of Nrf2," Antioxidants \& Redox Signaling, vol. 18, no. 15, pp. 1906-1919, 2013.

[58] Y.-C. Yang, C.-K. Lii, A.-H. Lin et al., "Induction of glutathione synthesis and heme oxygenase 1 by the flavonoids butein and phloretin is mediated through the ERK/Nrf2 pathway and protects against oxidative stress," Free Radical Biology \& Medicine, vol. 51, no. 11, pp. 2073-2081, 2011. 
[59] A. K. Bauer, T. Hill, C.-M. Alexander, and C.-M. Alexander, "The involvement of NRF2 in lung cancer," Oxidative Medicine and Cellular Longevity, vol. 2013, Article ID 746432, 10 pages, 2013.

[60] Y. R. Kim, O. JE, M. S. Kim et al., "Oncogenic NRF2 mutations in squamous cell carcinomas of oesophagus and skin," The Journal of Pathology, vol. 220, no. 4, pp. 446-451, 2010.

[61] P. A. Konstantinopoulos, D. Spentzos, E. Fountzilas et al., "Keap1 mutations and Nrf2 pathway activation in epithelial ovarian cancer," Cancer Research, vol. 71, no. 15, pp. 50815089, 2011.

[62] V. Malec, O. R. Gottschald, S. Li, F. Rose, W. Seeger, and J. Hänze, "HIF- $1 \alpha$ signaling is augmented during intermittent hypoxia by induction of the Nrf2 pathway in NOX1expressing adenocarcinoma A549 cells," Free Radical Biology \& Medicine, vol. 48, no. 12, pp. 1626-1635, 2010.

[63] S. K. Niture and A. K. Jaiswal, "Nrf2 protein up-regulates antiapoptotic protein Bcl-2 and prevents cellular apoptosis," Journal of Biological Chemistry, vol. 287, no. 13, pp. 98739886, 2012.

[64] W. Chen, Z. Sun, X.-J. Wang et al., "Direct interaction between Nrf2 and p21 Cip1/WAF1 upregulates the Nrf2mediated antioxidant response," Molecular Cell, vol. 34, no. 6, pp. 663-673, 2009.

[65] S. Kapeta, N. Chondrogianni, and E. S. Gonos, "Nuclear erythroid factor 2-mediated proteasome activation delays senescence in human fibroblasts," Journal of Biological Chemistry, vol. 285, no. 11, pp. 8171-8184, 2010.

[66] H. J. Jee, A. J. Kim, N. Song et al., "Nek6 overexpression antagonizes p53-induced senescence in human cancer cells," Cell Cycle, vol. 9, no. 23, pp. 4703-4710, 2010.

[67] M. Collado, J. Gil, A. Efeyan et al., "Tumour biology: senescence in premalignant tumours," Nature, vol. 436, no. 7051, p. $642,2005$.

[68] L. Jódar, E. M. Mercken, J. Ariza et al., "Genetic deletion of Nrf2 promotes immortalization and decreases life span of murine embryonic fibroblasts," The Journals of Gerontology: Series A, vol. 66A, no. 3, pp. 247-256, 2011.

[69] F. Shahidi and A. de Camargo, "Tocopherols and tocotrienols in common and emerging dietary sources: occurrence, applications, and health benefits," International Journal of Molecular Sciences, vol. 17, no. 10, p. 1745, 2016.

[70] B. S. McIntyre, K. P. Briski, A. Gapor, and P. W. Sylvester, "Antiproliferative and apoptotic effects of tocopherols and tocotrienols on preneoplastic and neoplastic mouse mammary epithelial cells," Proceedings of the Society for Experimental Biology and Medicine, vol. 224, no. 4, pp. 292-301, 2000.

[71] S. K. Park, B. G. Sanders, and K. Kline, "Tocotrienols induce apoptosis in breast cancer cell lines via an endoplasmic reticulum stress-dependent increase in extrinsic death receptor signaling," Breast Cancer Research and Treatment, vol. 124, no. 2, pp. 361-375, 2010.

[72] E. Pierpaoli, V. Viola, F. Pilolli, M. Piroddi, F. Galli, and M. Provinciali, " $\gamma$ - and $\delta$-tocotrienols exert a more potent anticancer effect than alpha-tocopheryl succinate on breast cancer cell lines irrespective of HER-2/neu expression," Life Sciences, vol. 86, pp. 668-675, 2010.

[73] G. V. Samant, V. B. Wali, and P. W. Sylvester, “Anti-proliferative effects of gamma-tocotrienol on mammary tumour cells are associated with suppression of cell cycle progression," Cell Proliferation, vol. 43, no. 1, pp. 77-83, 2010.
[74] T. Eitsuka, K. Nakagawa, and T. Miyazawa, "Down-regulation of telomerase activity in DLD-1 human colorectal adenocarcinoma cells by tocotrienol," Biochemical and Biophysical Research Communications, vol. 348, no. 1, pp. 170$175,2006$.

[75] A. Magnifico, L. Albano, S. Campaner et al., "Protein kinase $\mathrm{C} \alpha$ determines HER2 fate in breast carcinoma cells with HER2 protein overexpression without gene amplification," Cancer Research, vol. 67, no. 11, pp. 5308-5317, 2007.

[76] S. Makpol, L. W. Durani, K. H. Chua, Y. A. Mohd Yusof, and W. Z. Wan Ngah, "Tocotrienol-rich fraction prevents cell cycle arrest and elongates telomere length in senescent human diploid fibroblasts," Journal of Biomedicine and Biotechnology, vol. 2011, Article ID 506171, 11 pages, 2011.

[77] C. Berger, Y. Qian, and X. Chen, "The p53-estrogen receptor loop in cancer," Current Molecular Medicine, vol. 13, no. 8, pp. 1229-1240, 2013.

[78] K. Nesaretnam, P. Meganathan, S. D. Veerasenan, and K. R. Selvaduray, "Tocotrienols and breast cancer: the evidence to date," Genes \& Nutrition, vol. 7, no. 1, pp. 3-9, 2012.

[79] E. N. Georgousopoulou, D. B. Panagiotakos, D. D. Mellor, and N. Naumovski, "Tocotrienols, health and ageing: a systematic review," Maturitas, vol. 95, pp. 55-60, 2017.

[80] P. Meganathan and F. J-Y, "Biological properties of tocotrienols: evidence in human studies," International Journal of Molecular Sciences, vol. 17, no. 11, p. 1682, 2016.

[81] K. Nesaretnam, K. R. Selvaduray, G. Abdul Razak, S. D. Veerasenan, and P. A. Gomez, "Effectiveness of tocotrienol-rich fraction combined with tamoxifen in the management of women with early breast cancer: a pilot clinical trial," Breast Cancer Research, vol. 12, no. 5, 2010.

[82] G. M. Springett, K. Husain, A. Neuger et al., "A phase I safety, pharmacokinetic, and pharmacodynamic presurgical trial of vitamin $\mathrm{E} \delta$-tocotrienol in patients with pancreatic ductal neoplasia," eBioMedicine, vol. 2, no. 12, pp. 1987-1995, 2015.

[83] K. Nesaretnam, P. A. Gomez, K. R. Selvaduray, and G. A. Razak, "Tocotrienol levels in adipose tissue of benign and malignant breast lumps in patients in Malaysia," Asia Pacific Journal of Clinical Nutrition, vol. 16, no. 3, pp. 498-504, 2007.

[84] E. Balogun, M. Hoque, P. Gong et al., "Curcumin activates the haem oxygenase-1 gene via regulation of Nrf2 and the antioxidant-responsive element," Biochemical Journal, vol. 371, pp. 887-895, 2003.

[85] C. Lu, W. Xu, and S. Zheng, "Nrf2 activation is required for curcumin to induce lipocyte phenotype in hepatic stellate cells," Biomedicine \& Pharmacotherapy, vol. 95, pp. 1-10, 2017.

[86] A. Shehzad and Y. S. Lee, "Molecular mechanisms of curcumin action: signal transduction," BioFactors, vol. 39 , no. 1 , pp. 27-36, 2013.

[87] C. S. Beevers, L. Chen, L. Liu, Y. Luo, N. J. G. Webster, and S. Huang, "Curcumin disrupts the mammalian target of rapamycin-raptor complex," Cancer Research, vol. 69, no. 3, pp. 1000-1008, 2009.

[88] T. F. Wong, T. Takeda, B. Li et al., "Curcumin targets the AKT-mTOR pathway for uterine leiomyosarcoma tumor growth suppression," International Journal of Clinical Oncology, vol. 19, no. 2, pp. 354-363, 2014.

[89] Z. V. Chitikova, S. A. Gordeev, T. V. Bykova, S. G. Zubova, V. A. Pospelov, and T. V. Pospelova, "Sustained activation of DNA damage response in irradiated apoptosis-resistant 
cells induces reversible senescence associated with mTOR downregulation and expression of stem cell markers," Cell Cycle, vol. 13, no. 9, pp. 1424-1439, 2014.

[90] G. Mosieniak, M. A. Sliwinska, D. Przybylska et al., "Curcumin-treated cancer cells show mitotic disturbances leading to growth arrest and induction of senescence phenotype," The International Journal of Biochemistry \& Cell Biology, vol. 74, pp. 33-43, 2016.

[91] C. Ramachandran, H. B. Fonseca, P. Jhabvala, E. A. Escalon, and S. J. Melnick, "Curcumin inhibits telomerase activity through human telomerase reverse transcritpase in MCF-7 breast cancer cell line," Cancer Letters, vol. 184, no. 1, pp. 1-6, 2002.

[92] G. Mosieniak, M. Adamowicz, O. Alster et al., "Curcumin induces permanent growth arrest of human colon cancer cells: link between senescence and autophagy," Mechanisms of Ageing and Development, vol. 133, no. 6, pp. 444-455, 2012.

[93] S.-F. Hendrayani, H. H. Al-Khalaf, and A. Aboussekhra, "Curcumin triggers p16-dependent senescence in active breast cancer-associated fibroblasts and suppresses their paracrine procarcinogenic effects," Neoplasia, vol. 15, p. $631,2013$.

[94] S. C. Gupta, S. Patchva, and B. B. Aggarwal, "Therapeutic roles of curcumin: lessons learned from clinical trials," The AAPS Journal, vol. 15, no. 1, pp. 195-218, 2013.

[95] Z.-Y.He, C.-B. Shi, H. Wen, F. L. Li, B. L. Wang, and J. Wang, "Upregulation of p53 expression in patients with colorectal cancer by administration of curcumin," Cancer Investigation, vol. 29, no. 3, pp. 208-213, 2011.

[96] M. Kanai, K. Yoshimura, M. Asada et al., "A phase I/II study of gemcitabine-based chemotherapy plus curcumin for patients with gemcitabine-resistant pancreatic cancer," Cancer Chemotherapy and Pharmacology, vol. 68, no. 1, pp. 157-164, 2011.

[97] G. Belcaro, M. Hosoi, L. Pellegrini et al., "A controlled study of a lecithinized delivery system of curcumin (Meriva ${ }^{\circledR}$ ) to alleviate the adverse effects of cancer treatment," Phytotherapy Research, vol. 28, no. 3, pp. 444-450, 2014.

[98] J. C. W. Mak, "Potential role of green tea catechins in various disease therapies: progress and promise," Clinical and Experimental Pharmacology and Physiology, vol. 39, no. 3, pp. 265273, 2012.

[99] M. S. Butt, R. S. Ahmad, M. T. Sultan, M. M. N. Qayyum, and A. Naz, "Green tea and anticancer perspectives: updates from last decade," Critical Reviews in Food Science and Nutrition, vol. 55, no. 6, pp. 792-805, 2015.

[100] H.-K. Na and Y.-J. Surh, "Modulation of Nrf2-mediated antioxidant and detoxifying enzyme induction by the green tea polyphenol EGCG," Food and Chemical Toxicology, vol. 46, no. 4, pp. 1271-1278, 2008.

[101] J.-H. Shin, H.-J. Jeon, J. Park, and M.-S. Chang, "Epigallocatechin-3-gallate prevents oxidative stress-induced cellular senescence in human mesenchymal stem cells via Nrf2," International Journal of Molecular Medicine, vol. 38, no. 4, pp. 1075-1082, 2016.

[102] H. Yagi, J. Tan, and R. S. Tuan, "Polyphenols suppress hydrogen peroxide-induced oxidative stress in human bonemarrow derived mesenchymal stem cells," Journal of Cellular Biochemistry, vol. 114, no. 5, pp. 1163-1173, 2013.

[103] E. C. Stuart, M. J. Scandlyn, and R. J. Rosengren, "Role of epigallocatechin gallate (EGCG) in the treatment of breast and prostate cancer," Life Sciences, vol. 79, no. 25, pp. 23292336, 2006.

[104] P. Rajendran, E. Ho, D. E. Williams, and R. H. Dashwood, "Dietary phytochemicals, HDAC inhibition, and DNA damage/repair defects in cancer cells," Clinical Epigenetics, vol. 3, no. 1, p. 4, 2011.

[105] M. A. Sayeed, M. Bracci, R. Lazzarini et al., "Use of potential dietary phytochemicals to target miRNA: promising option for breast cancer prevention and treatment?," Journal of Functional Foods, vol. 28, pp. 177-193, 2017.

[106] A. M. Roy, M. S. Baliga, and S. K. Katiyar, "Epigallocatechin3 -gallate induces apoptosis in estrogen receptor-negative human breast carcinoma cells via modulation in protein expression of $\mathrm{p} 53$ and Bax and caspase- 3 activation," Molecular Cancer Therapeutics, vol. 4, no. 1, pp. 81-90, 2005.

[107] C.-H. Huang, S.-J. Tsai, Y.-J. Wang, M. H. Pan, J. Y. Kao, and T. D. Way, "EGCG inhibits protein synthesis, lipogenesis, and cell cycle progression through activation of AMPK in p53 positive and negative human hepatoma cells," Molecular Nutrition \& Food Research, vol. 53, no. 9, pp. 1156-1165, 2009.

[108] A. Puissant and P. Auberger, "AMPK- and p62/SQSTM1dependent autophagy mediate resveratrol-induced cell death in chronic myelogenous leukemia," Autophagy, vol. 6, no. 5, pp. 655-657, 2010.

[109] I. Naasani, H. Seimiya, and T. Tsuruo, "Telomerase inhibition, telomere shortening, and senescence of cancer cells by tea catechins," Biochemical and Biophysical Research Communications, vol. 249, no. 2, pp. 391-396, 1998.

[110] J. B. Berletch, C. Liu, W. K. Love, L. G. Andrews, S. K. Katiyar, and T. O. Tollefsbol, "Epigenetic and genetic mechanisms contribute to telomerase inhibition by EGCG," Journal of Cellular Biochemistry, vol. 103, no. 2, pp. 509-519, 2008.

[111] A. Aliper, A. V. Belikov, A. Garazha et al., "In search for geroprotectors: in silico screening and in vitro validation of signalome-level mimetics of young healthy state," Aging, vol. 8, no. 9, pp. 2127-2152, 2016.

[112] E. Lecumberri, Y. M. Dupertuis, R. Miralbell, and C. Pichard, "Green tea polyphenol epigallocatechin-3-gallate (EGCG) as adjuvant in cancer therapy," Clinical Nutrition, vol. 32, pp. 894-903, 2013.

[113] A. Granja, M. Pinheiro, and S. Reis, "Epigallocatechin gallate nanodelivery systems for cancer therapy," Nutrients, vol. 8, no. 5, p. 307, 2016.

[114] H. Zhao, W. Zhu, P. Xie et al., "A phase I study of concurrent chemotherapy and thoracic radiotherapy with oral epigallocatechin-3-gallate protection in patients with locally advanced stage III non-small-cell lung cancer," Radiotherapy and Oncology, vol. 110, no. 1, pp. 132-136, 2014.

[115] E. B. Golden, P. Y. Lam, A. Kardosh et al., "Green tea polyphenols block the anticancer effects of bortezomib and other boronic acid-based proteasome inhibitors," Blood, vol. 113, no. 23, pp. 5927-5937, 2009.

[116] M. J. Lee, Z. Y. Wang, H. Li et al., "Analysis of plasma and urinary tea polyphenols in human subjects," Cancer Epidemiology Biomarkers \& Prevention, vol. 4, no. 4, pp. 393-399, 1995.

[117] M. A. Sayeed, M. Bracci, G. Lucarini, R. Lazzarini, R. Di Primio, and L. Santarelli, "Regulation of microRNA using promising dietary phytochemicals: possible preventive and treatment option of malignant mesothelioma," Biomedicine \& Pharmacotherapy, vol. 94, pp. 1197-1224, 2017. 
[118] S. Chen, H. Jiang, X. Wu, and J. Fang, "Therapeutic effects of quercetin on inflammation, obesity, and type 2 diabetes," Mediators of Inflammation, vol. 2016, Article ID 9340637, 5 pages, 2016.

[119] D. Kashyap, S. Mittal, K. Sak, P. Singhal, and H. S. Tuli, "Molecular mechanisms of action of quercetin in cancer: recent advances," Tumor Biology, vol. 37, no. 10, pp. 1292712939, 2016.

[120] C. L. L. Saw, Y. Guo, A. Y. Yang et al., "The berry constituents quercetin, kaempferol, and pterostilbene synergistically attenuate reactive oxygen species: involvement of the Nrf2ARE signaling pathway," Food and Chemical Toxicology, vol. 72, pp. 303-311, 2014.

[121] S. Tanigawa, M. Fujii, and D.-X. Hou, "Action of Nrf2 and Keap1 in ARE-mediated NQO1 expression by quercetin," Free Radical Biology \& Medicine, vol. 42, pp. 1690-1703, 2007.

[122] P. Yao, A. Nussler, L. Liu et al., "Quercetin protects human hepatocytes from ethanol-derived oxidative stress by inducing heme oxygenase-1 via the MAPK/Nrf2 pathways," Journal of Hepatology, vol. 47, no. 2, pp. 253-261, 2007.

[123] N. Chondrogianni, S. Kapeta, I. Chinou, K. Vassilatou, I. Papassideri, and E. S. Gonos, "Anti-ageing and rejuvenating effects of quercetin,” Experimental Gerontology, vol. 45, no. 10, pp. 763-771, 2010.

[124] N. Hasima and B. Ozpolat, "Regulation of autophagy by polyphenolic compounds as a potential therapeutic strategy for cancer," Cell Death \& Disease, vol. 5, no. 11, article e1509, 2014.

[125] A. J. Vargas, S. Sittadjody, T. Thangasamy, E. E. Mendoza, K. H. Limesand, and R. Burd, "Exploiting tyrosinase expression and activity in melanocytic tumors: quercetin and the central role of p53," Integrative Cancer Therapies, vol. 10, no. 4, pp. 328-340, 2011.

[126] K. W. Lee, A. M. Bode, and Z. Dong, "Molecular targets of phytochemicals for cancer prevention," Nature Reviews Cancer, vol. 11, no. 3, pp. 211-218, 2011.

[127] Y. Q. Wei, X. Zhao, Y. Kariya, H. Fukata, K. Teshigawara, and A. Uchida, "Induction of apoptosis by quercetin: involvement of heat shock protein," Cancer Research, vol. 54, no. 18, 1994.

[128] L. L. Zamin, E. C. Filippi-Chiela, P. Dillenburg-Pilla, F. Horn, C. Salbego, and G. Lenz, "Resveratrol and quercetin cooperate to induce senescence-like growth arrest in C6 rat glioma cells," Cancer Science, vol. 100, no. 9, pp. 1655-1662, 2009.

[129] J. E. Vargas, E. C. Filippi-Chiela, T. Suhre, F. C. Kipper, D. Bonatto, and G. Lenz, "Inhibition of HDAC increases the senescence induced by natural polyphenols in glioma cells," Biochemistry and Cell Biology, vol. 92, no. 4, pp. 297304, 2014.

[130] S. Tanigawa, M. Fujii, and D.-X. Hou, "Stabilization of p53 is involved in quercetin-induced cell cycle arrest and apoptosis in HepG2 cells," Bioscience, Biotechnology, and Biochemistry, vol. 72, no. 3, pp. 797-804, 2008.

[131] M. Russo, C. Spagnuolo, I. Tedesco, S. Bilotto, and G. L. Russo, "The flavonoid quercetin in disease prevention and therapy: facts and fancies," Biochemical Pharmacology, vol. 83, no. 1, pp. 6-15, 2012.

[132] D. R. Ferry, A. Smith, J. Malkhandi et al., "Phase I clinical trial of the flavonoid quercetin: pharmacokinetics and evidence for in vivo tyrosine kinase inhibition," Clinical Cancer Research, vol. 2, no. 4, pp. 659-668, 1996.
[133] P. B. Kaufman, J. A. Duke, H. Brielmann, J. Boik, and J. E. Hoyt, "A comparative survey of leguminous plants as sources of the isoflavones, genistein and daidzein: implications for human nutrition and health," The Journal of Alternative and Complementary Medicine, vol. 3, no. 1, pp. 7-12, 1997.

[134] N. Behloul and G. Wu, "Genistein: a promising therapeutic agent for obesity and diabetes treatment," European Journal of Pharmacology, vol. 698, no. 1-3, pp. 31-38, 2013.

[135] M. A. Rahman Mazumder and P. Hongsprabhas, "Genistein as antioxidant and antibrowning agents in in vivo and in vitro: a review," Biomedicine \& Pharmacotherapy, vol. 82, pp. 379-392, 2016.

[136] C. Spagnuolo, G. L. Russo, I. E. Orhan et al., "Genistein and cancer: current status, challenges, and future directions," Advances in Nutrition: An International Review Journal, vol. 6, no. 4, pp. 408-419, 2015.

[137] F. Yuan-Jing, W. Wei, L. Jian-Ping, J. Yu-Xia, and D. Zi-Ling, "Genistein promotes the metabolic transformation of acetaminophen to glucuronic acid in human L-O2, HepG2 and Hep3b cells via the Nrf2/Keap1 pathway," Food \& Function, vol. 7, no. 11, pp. 4683-4692, 2016.

[138] X. Zhai, M. Lin, F. Zhang et al., "Dietary flavonoid genistein induces $\mathrm{Nrf} 2$ and phase II detoxification gene expression via ERKs and PKC pathways and protects against oxidative stress in Caco-2 cells," Molecular Nutrition \& Food Research, vol. 57, no. 2, pp. 249-259, 2013.

[139] K. Y. Lee, J.-R. Kim, and H. C. Choi, "Genistein-induced LKB1-AMPK activation inhibits senescence of VSMC through autophagy induction," Vascular Pharmacology, vol. 81, pp. 75-82, 2016.

[140] M. N. Chau, L. H. El Touny, S. Jagadeesh, and P. P. Banerjee, "Physiologically achievable concentrations of genistein enhance telomerase activity in prostate cancer cells via the activation of STAT3," Carcinogenesis, vol. 28, no. 11, pp. 22822290, 2007.

[141] H. Gali-Muhtasib, R. Hmadi, M. Kareh, R. Tohme, and N. Darwiche, "Cell death mechanisms of plant-derived anticancer drugs: beyond apoptosis," Apoptosis, vol. 20, no. 12, pp. 1531-1562, 2015.

[142] Y. Li, S. Upadhyay, M. Bhuiyan, and F. H. Sarkar, "Induction of apoptosis in breast cancer cells MDA-MB-231 by genistein," Oncogene, vol. 18, no. 20, pp. 3166-3172, 1999.

[143] F. Lian, M. Bhuiyan, Y. W. Li, N. Wall, M. Kraut, and F. H. Sarkar, "Genistein-induced G2-M arrest, p21 ${ }^{\text {WAF1 }}$ upregulation, and apoptosis in a non-small-cell lung cancer cell line," Nutrition \& Cancer, vol. 31, no. 3, pp. 184-191, 1998.

[144] G. Shafiee, M. Saidijam, H. Tavilani, N. Ghasemkhani, and I. Khodadadi, "Genistein induces apoptosis and inhibits proliferation of HT29 colon cancer cells," International Journal of Molecular and Cellular Medicine, vol. 5, no. 3, pp. 178191, 2016.

[145] X. Liu, C. Sun, X. Jin et al., "Genistein enhances the radiosensitivity of breast cancer cells via $G_{2} / M$ cell cycle arrest and apoptosis," Molecules, vol. 18, no. 11, pp. 1320013217, 2013.

[146] X. X. Liu, C. Sun, X. D. Jin et al., "Genistein sensitizes sarcoma cells in vitro and in vivo by enhancing apoptosis and by inhibiting DSB repair pathways," Journal of Radiation Research, vol. 57, no. 3, pp. 227-237, 2016.

[147] Y. Li, H. Chen, T. M. Hardy, and T. O. Tollefsbol, "Epigenetic regulation of multiple tumor-related genes leads to 
suppression of breast tumorigenesis by dietary genistein," PLoS One, vol. 8, no. 1, article e54369, 2013.

[148] S. Majid, N. Kikuno, J. Nelles et al., "Genistein induces the p21WAF1/CIP1 and p16INK4a tumor suppressor genes in prostate cancer cells by epigenetic mechanisms involving active chromatin modification," Cancer Research, vol. 68, no. 8, pp. 2736-2744, 2008.

[149] Z. Zhang, C.-Z. Wang, D. G-J et al., "Genistein induces G2/M cell cycle arrest and apoptosis via ATM/p53-dependent pathway in human colon cancer cells," International Journal of Oncology, vol. 43, no. 1, pp. 289-296, 2013.

[150] J. Zhu, C. Zhang, Y. Qing et al., "Genistein induces apoptosis by stabilizing intracellular p53 protein through an APE1mediated pathway," Free Radical Biology \& Medicine, vol. 86, pp. 209-218, 2015.

[151] A. K. Khaw, J. W. Y. Yong, G. Kalthur, and M. P. Hande, "Genistein induces growth arrest and suppresses telomerase activity in brain tumor cells," Genes, Chromosomes \& Cancer, vol. 51, no. 10, pp. 961-974, 2012.

[152] F. Spinozzi, M. C. Pagliacci, G. Migliorati et al., "The natural tyrosine kinase inhibitor genistein produces cell cycle arrest and apoptosis in Jurkat T-leukemia cells," Leukemia Research, vol. 18, no. 6, pp. 431-439, 1994.

[153] C. K. Taylor, R. M. Levy, J. C. Elliott, and B. P. Burnett, “The effect of genistein aglycone on cancer and cancer risk: a review of in vitro, preclinical, and clinical studies," Nutrition Reviews, vol. 67, no. 7, pp. 398-415, 2009.

[154] M. Provinciali, F. Re, A. Donnini et al., "Effect of resveratrol on the development of spontaneous mammary tumors in HER-2/neu transgenic mice," International Journal of Cancer, vol. 115, no. 1, pp. 36-45, 2005.

[155] M. Jang, L. Cai, G. O. Udeani et al., "Cancer chemopreventive activity of resveratrol, a natural product derived from grapes," Science, vol. 275, no. 5297, pp. 218-220, 1997.

[156] B. Singh, R. Shoulson, A. Chatterjee et al., "Resveratrol inhibits estrogen-induced breast carcinogenesis through induction of NRF2-mediated protective pathways," Carcinogenesis, vol. 35, no. 8, pp. 1872-1880, 2014.

[157] K. P. Bhat, D. Lantvit, K. Christov, R. G. Mehta, R. C. Moon, and J. M. Pezzuto, "Estrogenic and antiestrogenic properties of resveratrol in mammary tumor models," Cancer Research, vol. 61, no. 20, pp. 7456-7463, 2001.

[158] F. Scarlatti, G. Sala, G. Somenzi, P. Signorelli, N. Sacchi, and R. Ghidoni, "Resveratrol induces growth inhibition and apoptosis in metastatic breast cancer cells via de novo ceramide signaling," The FASEB Journal, vol. 17, pp. 2339-2341, 2003.

[159] Q. Wang, H. Li, X.-W. Wang, D. Wu, X. Y. Chen, and J. Liu, "Resveratrol promotes differentiation and induces Fasindependent apoptosis of human medulloblastoma cells," Neuroscience Letters, vol. 351, no. 2, pp. 83-86, 2003.

[160] A. K. Joe, H. Liu, M. Suzui, M. E. Vural, D. Xiao, and I. B. Weinstein, "Resveratrol induces growth inhibition, S-phase arrest, apoptosis, and changes in biomarker expression in several human cancer cell lines," Clinical Cancer Research, vol. 8, no. 3, pp. 893-903, 2002.

[161] Q. Yang, B. Wang, W. Zang et al., "Resveratrol inhibits the growth of gastric cancer by inducing G1 phase arrest and senescence in a Sirt1-dependent manner," PLoS One, vol. 8, article e70627, 2013.

[162] I. Ali and D. P. Braun, "Resveratrol enhances mitomycin C-mediated suppression of human colorectal cancer cell proliferation by up-regulation of p21WAF1/CIP1," Anticancer Research, vol. 34, no. 10, pp. 5439-5446, 2014.

[163] A. Bishayee, T. Politis, and A. S. Darvesh, "Resveratrol in the chemoprevention and treatment of hepatocellular carcinoma," Cancer Treatment Reviews, vol. 36, no. 1, pp. 43-53, 2010.

[164] M. E. Juan, I. Alfaras, and J. M. Planas, "Colorectal cancer chemoprevention by trans-resveratrol," Pharmacological Research, vol. 65, no. 6, pp. 584-591, 2012.

[165] H. Cai, E. Scott, A. Kholghi et al., "Cancer chemoprevention: evidence of a nonlinear dose response for the protective effects of resveratrol in humans and mice," Science Translational Medicine, vol. 7, no. 298, article 298ra117, 2015.

[166] H. Luo, A. Yang, B. A. Schulte, M. J. Wargovich, and G. Y. Wang, "Resveratrol induces premature senescence in lung cancer cells via ROS-mediated DNA damage," PLoS One, vol. 8, no. 3, article e60065, 2013.

[167] G. Lanzilli, M. P. Fuggetta, M. Tricarico et al., "Resveratrol down-regulates the growth and telomerase activity of breast cancer cells in vitro," International Journal of Oncology, vol. 28, no. 3, pp. 641-648, 2006.

[168] M. P. Fuggetta, G. Lanzilli, M. Tricarico et al., "Effect of resveratrol on proliferation and telomerase activity of human colon cancer cells in vitro," Journal of Experimental \& Clinical Cancer Research, vol. 25, no. 2, pp. 189-193, 2006.

[169] A. Bhardwaj, G. Sethi, S. Vadhan-Raj et al., "Resveratrol inhibits proliferation, induces apoptosis, and overcomes chemoresistance through down-regulation of STAT3 and nuclear factor- B-regulated antiapoptotic and cell survival gene products in human multiple myeloma cells," Blood, vol. 109, no. 6, pp. 2293-2302, 2007.

[170] R. Popat, T. Plesner, F. Davies et al., "A phase 2 study of SRT501 (resveratrol) with bortezomib for patients with relapsed and or refractory multiple myeloma," British Journal of Haematology, vol. 160, no. 5, pp. 714-717, 2013.

[171] L. M. Howells, D. P. Berry, P. J. Elliott et al., "Phase I randomized, double-blind pilot study of micronized resveratrol (SRT501) in patients with hepatic metastases-safety, pharmacokinetics, and pharmacodynamics," Cancer Prevention Research, vol. 4, pp. 1419-1425, 2011.

[172] K. Filippopoulou, N. Papaevgeniou, M. Lefaki et al., "2,3dehydrosilybin $\mathrm{A} / \mathrm{B}$ as a pro-longevity and anti-aggregation compound," Free Radical Biology \& Medicine, vol. 103, pp. 256-267, 2017.

[173] J. Kumar, K.-C. Park, A. Awasthi, and B. Prasad, "Silymarin extends lifespan and reduces proteotoxicity in C. elegans Alzheimer's model," CNS \& Neurological Disorder Drug Targets, vol. 14, pp. 295-302, 2015.

[174] M. F. M. Sciacca, V. Romanucci, A. Zarrelli et al., "Inhibition of $\mathrm{A} \beta$ amyloid growth and toxicity by silybins: the crucial role of stereochemistry," ACS Chemical Neuroscience, vol. 8, no. 8, pp. 1767-1778, 2017.

[175] A. Y. Au, J. M. Hasenwinkel, and C. G. Frondoza, "Hepatoprotective effects of S-adenosylmethionine and silybin on canine hepatocytes in vitro," Journal of Animal Physiology and Animal Nutrition, vol. 97, no. 2, pp. 331-341, 2013.

[176] C. Agarwal, R. P. Singh, S. Dhanalakshmi et al., "Silibinin upregulates the expression of cyclin-dependent kinase inhibitors and causes cell cycle arrest and apoptosis in human colon carcinoma HT-29 cells," Oncogene, vol. 22, no. 51, pp. 8271-8282, 2003. 
[177] A. Tyagi, C. Agarwal, G. Harrison, L. M. Glode, and R. Agarwal, "Silibinin causes cell cycle arrest and apoptosis in human bladder transitional cell carcinoma cells by regulating CDKI-CDK-cyclin cascade, and caspase 3 and PARP cleavages," Carcinogenesis, vol. 25, no. 9, pp. 1711-1720, 2004.

[178] X. Zi and R. Agarwal, "Silibinin decreases prostate-specific antigen with cell growth inhibition via $G_{1}$ arrest, leading to differentiation of prostate carcinoma cells: implications for prostate cancer intervention," Proceedings of the National Academy of Sciences of the United States of America, vol. 96, no. 13, pp. 7490-7495, 1999.

[179] M. Provinciali, F. Papalini, F. Orlando et al., "Effect of the silybin-phosphatidylcholine complex (IdB 1016) on the development of mammary tumors in HER-2/neu transgenic mice," Cancer Research, vol. 67, no. 5, pp. 2022-2029, 2007.

[180] T. W. Flaig, M. Glodé, D. Gustafson et al., "A study of highdose oral silybin-phytosome followed by prostatectomy in patients with localized prostate cancer," The Prostate, vol. 70, 2010.

[181] M. Lazzeroni, A. Guerrieri-Gonzaga, S. Gandini et al., “A presurgical study of oral silybin-phosphatidylcholine in patients with early breast cancer," Cancer Prevention Research, vol. 9, no. 1, pp. 89-95, 2016.

[182] A. B. Siegel, R. Narayan, R. Rodriguez et al., "A phase I dosefinding study of silybin phosphatidylcholine (milk thistle) in patients with advanced hepatocellular carcinoma," Integrative Cancer Therapies, vol. 13, no. 1, pp. 46-53, 2014.

[183] P. Gupta, S. E. Wright, S.-H. Kim, and S. K. Srivastava, "Phenethyl isothiocyanate: a comprehensive review of anti-cancer mechanisms," Biochimica et Biophysica Acta (BBA) - Reviews on Cancer, vol. 1846, no. 2, pp. 405-424, 2014.

[184] V. Krajka-Kuźniak, J. Paluszczak, H. Szaefer, and W. BaerDubowska, "The activation of the Nrf2/ARE pathway in HepG2 hepatoma cells by phytochemicals and subsequent modulation of phase II and antioxidant enzyme expression," Journal of Physiology and Biochemistry, vol. 71, no. 2, pp. 227-238, 2015.

[185] D. Trachootham, Y. Zhou, H. Zhang et al., "Selective killing of oncogenically transformed cells through a ROS-mediated mechanism by $\beta$-phenylethyl isothiocyanate," Cancer Cell, vol. 10, no. 3, pp. 241-252, 2006.

[186] N. Roy, I. Elangovan, D. Kopanja, S. Bagchi, and P. Raychaudhuri, "Tumor regression by phenethyl isothiocyanate involves DDB2," Cancer Biology \& Therapy, vol. 14, no. 2, pp. 108-116, 2013.

[187] J. M. Pullar, S. J. Thomson, M. J. King, C. I. Turnbull, R. G. Midwinter, and M. B. Hampton, "The chemopreventive agent phenethyl isothiocyanate sensitizes cells to Fasmediated apoptosis," Carcinogenesis, vol. 25, no. 5, pp. 765772, 2003.

[188] M. Aggarwal, R. Saxena, E. Sinclair et al., "Reactivation of mutant p53 by a dietary-related compound phenethyl isothiocyanate inhibits tumor growth," Cell Death and Differentiation, vol. 23, no. 10, pp. 1615-1627, 2016.

[189] R. Sarkars, S. Mukherjee, and M. Roy, "Targeting heat shock proteins by phenethyl isothiocyanate results in cell-cycle arrest and apoptosis of human breast cancer cells," Nutrition and Cancer, vol. 65, no. 3, pp. 480-493, 2013.

[190] Y.-T. Yeh, H. Yeh, S. S-H et al., "Phenethyl isothiocyanate induces DNA damage-associated G2/M arrest and subsequent apoptosis in oral cancer cells with varying p53 mutations," Free Radical Biology \& Medicine, vol. 74, pp. 113, 2014.

[191] D. Zhou, Y. Wang, J. Chang, L. Shao, Y. Luo, and W. Feng, "Compositions and methods for inhibiting antiapoptotic bcl-2 proteins as anti-aging agents. PCT Int Appl 124pp," 2015, US 20170056421 A1, 2017.

[192] J.-M. Yuan, I. Stepanov, S. E. Murphy et al., "Clinical trial of 2-phenethyl isothiocyanate as an inhibitor of metabolic activation of a tobacco-specific lung carcinogen in cigarette smokers," Cancer Prevention Research, vol. 9, no. 5, pp. 396-405, 2016.

[193] Y. Zhang, P. Talalay, C. G. Cho, and G. H. Posner, "A major inducer of anticarcinogenic protective enzymes from broccoli: isolation and elucidation of structure," Proceedings of the National Academy of Sciences of the United States of America, vol. 89, no. 6, pp. 2399-2403, 1992.

[194] W.-S. Jeong, Y.-S. Keum, C. Chen et al., "Differential expression and stability of endogenous nuclear factor E2-related factor 2 (Nrf2) by natural chemopreventive compounds in HepG2 human hepatoma cells," BMB Reports, vol. 38, no. 2, pp. 167-176, 2005.

[195] C. Xu, M.-T. Huang, G. Shen et al., "Inhibition of 7,12dimethylbenz $(a)$ anthracene-induced skin tumorigenesis in C57BL/6 mice by sulforaphane is mediated by nuclear factor E2-related factor 2," Cancer Research, vol. 66, no. 16, pp. 8293-8296, 2006.

[196] X. Jiang, Y. Bai, Z. Zhang, Y. Xin, and L. Cai, "Protection by sulforaphane from type 1 diabetes-induced testicular apoptosis is associated with the up-regulation of Nrf2 expression and function," Toxicology and Applied Pharmacology, vol. 279, no. 2, pp. 198-210, 2014.

[197] Z. Jiao, J. Chang, J. Li, D. Nie, H. Cui, and D. Guo, "Sulforaphane increases $\mathrm{Nrf} 2$ expression and protects alveolar epithelial cells against injury caused by cigarette smoke extract," Molecular Medicine Reports, vol. 16, pp. 12411247, 2017.

[198] B. S. Cornblatt, L. Ye, A. T. Dinkova-Kostova et al., "Preclinical and clinical evaluation of sulforaphane for chemoprevention in the breast," Carcinogenesis, vol. 28, no. 7, pp. 1485-1490, 2007.

[199] F. Zanichelli, S. Capasso, M. Cipollaro et al., "Dose-dependent effects of R-sulforaphane isothiocyanate on the biology of human mesenchymal stem cells, at dietary amounts, it promotes cell proliferation and reduces senescence and apoptosis, while at anti-cancer drug doses, it has a cytotoxic effect," Age, vol. 34, no. 2, pp. 281-293, 2012.

[200] A. Lewinska, J. Adamczyk-Grochala, A. Deregowska, and M. Wnuk, "Sulforaphane-induced cell cycle arrest and senescence are accompanied by DNA hypomethylation and changes in microRNA profile in breast cancer cells," Theranostics, vol. 7, no. 14, pp. 3461-3477, 2017.

[201] R. H. Dashwood and E. Ho, "Dietary agents as histone deacetylase inhibitors: sulforaphane and structurally related isothiocyanates," Nutrition Reviews, vol. 66, pp. S36-S38, 2008.

[202] M. C. Myzak, P. A. Karplus, F.-L. Chung, and R. H. Dashwood, "A novel mechanism of chemoprotection by sulforaphane," Cancer Research, vol. 64, no. 16, pp. 57675774, 2004.

[203] M. C. Myzak, W. M. Dashwood, G. A. Orner, E. Ho, and R. H. Dashwood, "Sulforaphane inhibits histone deacetylase in vivo and suppresses tumorigenesis in $A p c^{\mathrm{min}}$ mice," The FASEB Journal, vol. 20, no. 3, pp. 506-508, 2006. 
[204] S. M. Meeran, S. N. Patel, and T. O. Tollefsbol, "Sulforaphane causes epigenetic repression of hTERT expression in human breast cancer cell lines," PLoS One, vol. 5, no. 7, article e11457, 2010.

[205] G. Pappa, H. Bartsch, and C. Gerhäuser, "Biphasic modulation of cell proliferation by sulforaphane at physiologically relevant exposure times in a human colon cancer cell line," Molecular Nutrition \& Food Research, vol. 51, no. 8, pp. 977-984, 2007.

[206] K.-M. Choi, Y.-S. Lee, D.-M. Sin et al., "Sulforaphane inhibits mitotic clonal expansion during adipogenesis through cell cycle arrest," Obesity, vol. 20, no. 7, pp. 1365-1371, 2012.

[207] M. Russo, C. Spagnuolo, G. L. Russo et al., "Nrf2 targeting by sulforaphane: a potential therapy for cancer treatment," Critical Reviews in Food Science and Nutrition, pp. 1-15, 2016.

[208] J. J. Alumkal, R. Slottke, J. Schwartzman et al., “A phase II study of sulforaphane-rich broccoli sprout extracts in men with recurrent prostate cancer," Investigational New Drugs, vol. 33, no. 2, pp. 480-489, 2015.

[209] B. G. Cipolla, E. Mandron, J. M. Lefort et al., "Effect of sulforaphane in men with biochemical recurrence after radical prostatectomy," Cancer Prevention Research, vol. 8, no. 8, pp. 712-719, 2015.

[210] C. Meng, H. Zhu, H. Song et al., "Targets and molecular mechanisms of triptolide in cancer therapy," Chinese Journal of Cancer Research, vol. 26, no. 5, pp. 622-626, 2014.

[211] J. Liu, M. Shen, Z. Yue et al., "Triptolide inhibits colon-rectal cancer cells proliferation by induction of G1 phase arrest through upregulation of p21," Phytomedicine, vol. 19, no. 89, pp. 756-762, 2012.

[212] Y.-Y. Sun, L. Xiao, D. Wang et al., "Triptolide inhibits viability and induces apoptosis in liver cancer cells through activation of the tumor suppressor gene p53," International Journal of Oncology, vol. 50, no. 3, pp. 847-852, 2017.

[213] J. Wu, Q. Q. Li, H. Zhou et al., "Selective tumor cell killing by triptolide in p53 wild-type and p53 mutant ovarian carcinomas," Medical Oncology, vol. 31, no. 7, p. 14, 2014.

[214] F. Chen, Y. Liu, S. Wang et al., "Triptolide, a Chinese herbal extract, enhances drug sensitivity of resistant myeloid leukemia cell lines through downregulation of HIF-1 $\alpha$ and Nrf2," Pharmacogenomics, vol. 14, no. 11, pp. 1305-1317, 2013.

[215] R. Li, X. Zhang, X. Tian et al., "Triptolide inhibits tumor growth by induction of cellular senescence," Oncology Reports, vol. 37, no. 1, pp. 442-448, 2017.

[216] T. M. Kiviharju, P. S. Lecane, R. G. Sellers, and D. M. Peehl, "Antiproliferative and proapoptotic activities of triptolide (PG490), a natural product entering clinical trials, on primary cultures of human prostatic epithelial cells," Clinical Cancer Research, vol. 8, no. 8, pp. 2666-2674, 2002.

[217] S. Yang, M. Zhang, C. Chen et al., "Triptolide mitigates radiation-induced pulmonary fibrosis," Radiation Research, vol. 184, no. 5, pp. 509-517, 2015.

[218] J. Pan, D. Li, Y. Xu et al., "Inhibition of Bcl-2/xl with ABT263 selectively kills senescent type II pneumocytes and reverses persistent pulmonary fibrosis induced by ionizing radiation in mice," International Journal of Radiation Oncology Biology Physics, vol. 99, no. 2, pp. 353-361, 2017.

[219] J. J. E. M. Kitzen, M. J. A. de Jonge, C. H. J. Lamers et al., "Phase I dose-escalation study of F60008, a novel apoptosis inducer, in patients with advanced solid tumours," European Journal of Cancer, vol. 45, no. 10, pp. 1764-1772, 2009.
[220] J. Y.-Y. Chan, A. C.-Y. Yuen, R. Y.-K. Chan, and S.-W. Chan, "A review of the cardiovascular benefits and antioxidant properties of allicin," Phytotherapy Research, vol. 27, no. 5, pp. 637-646, 2013.

[221] M. Zhang, H. Pan, Y. Xu, X. Wang, Z. Qiu, and L. Jiang, "Allicin decreases lipopolysaccharide-induced oxidative stress and inflammation in human umbilical vein endothelial cells through suppression of mitochondrial dysfunction and activation of Nrf2," Cellular Physiology and Biochemistry, vol. 41, no. 6, pp. 2255-2267, 2017.

[222] R. Lv, N. Mao, J. Wu et al., "Neuroprotective effect of allicin in a rat model of acute spinal cord injury," Life Sciences, vol. 143, pp. 114-123, 2015.

[223] M. C. H. Gruhlke, C. Nicco, F. Batteux, and A. J. Slusarenko, "The effects of allicin, a reactive sulfur species from garlic, on a selection of mammalian cell lines," Antioxidants, vol. 6, no. 1, p. 1, 2016.

[224] Y.-L. Chu, C.-T. Ho, J.-G. Chung, R. Raghu, Y. C. Lo, and L. Y. Sheen, "Allicin induces anti-human liver cancer cells through the p53 gene modulating apoptosis and autophagy," Journal of Agricultural and Food Chemistry, vol. 61, no. 41, pp. 9839-9848, 2013.

[225] L. Sun and X. Wang, "Effects of allicin on both telomerase activity and apoptosis in gastric cancer SGC-7901 cells," World Journal of Gastroenterology, vol. 9, no. 9, pp. 1930-1934, 2003.

[226] M. Imanshahidi and H. Hosseinzadeh, "Pharmacological and therapeutic effects of Berberis vulgaris and its active constituent, berberine," Phytotheraphy Research, vol. 22, no. 8, pp. 999-1012, 2008.

[227] M. Tillhon, L. M. Guamán Ortiz, P. Lombardi, and A. I. Scovassi, "Berberine: new perspectives for old remedies," Biochemical Pharmacology, vol. 84, pp. 1260-1267, 2012.

[228] C. Mo, L. Wang, J. Zhang et al., “The crosstalk between Nrf2 and AMPK signal pathways is important for the antiinflammatory effect of berberine in LPS-stimulated macrophages and endotoxin-shocked mice," Antioxidants \& Redox Signaling, vol. 20, no. 4, pp. 574-588, 2014.

[229] X. Zhang, D. Liang, X. Lian et al., "Berberine activates Nrf2 nuclear translocation and inhibits apoptosis induced by high glucose in renal tubular epithelial cells through a phosphatidylinositol 3-kinase/Akt-dependent mechanism," Apoptosis, vol. 21, no. 6, pp. 721-736, 2016.

[230] J. Bao, B. Huang, L. Zou et al., "Hormetic effect of berberine attenuates the anticancer activity of chemotherapeutic agents," PLoS One, vol. 10, no. 9, article e0139298, 2015.

[231] P. Jabbarzadeh Kaboli, A. Rahmat, P. Ismail, and K.-H. Ling, "Targets and mechanisms of berberine, a natural drug with potential to treat cancer with special focus on breast cancer," European Journal of Pharmacology, vol. 740, pp. 584-595, 2014.

[232] S. Letasiová, S. Jantová, L. Cipák, and M. Múcková, “Berberineantiproliferative activity in vitro and induction of apoptosis/ necrosis of the U937 and B16 cells," Cancer Letters, vol. 239, no. 2, pp. 254-262, 2006.

[233] C.-C. Lin, S.-T. Kao, G.-W. Chen, H. C. Ho, and J. G. Chung, "Apoptosis of human leukemia HL-60 cells and murine leukemia WEHI-3 cells induced by berberine through the activation of caspase-3," Anticancer Research, vol. 26, no. 1A, pp. 227-242, 2006.

[234] K.-H. Lee, H.-L. Lo, W.-C. Tang, H. H. Y. Hsiao, and P. M. Yang, "A gene expression signature-based approach reveals 
the mechanisms of action of the Chinese herbal medicine berberine," Scientific Reports, vol. 4, no. 1, article 6394, 2014.

[235] L. M. G. Ortiz, P. Lombardi, M. Tillhon, and A. I. Scovassi, "Berberine, an epiphany against cancer," Molecules, vol. 19, no. 8, pp. 12349-12367, 2014.

[236] Q. Liu, X. Xu, M. Zhao et al., "Berberine induces senescence of human glioblastoma cells by downregulating the EGFRMEK-ERK signaling pathway," Molecular Cancer Therapeutics, vol. 14, no. 2, pp. 355-363, 2015.

[237] E. Pierpaoli, A. G. Arcamone, F. Buzzetti, P. Lombardi, C. Salvatore, and M. Provinciali, "Antitumor effect of novel berberine derivatives in breast cancer cells," BioFactors, vol. 39, no. 6, pp. 672-679, 2013.

[238] C. Bazzicalupi, M. Ferraroni, A. R. Bilia, F. Scheggi, and P. Gratteri, "The crystal structure of human telomeric DNA complexed with berberine: an interesting case of stacked ligand to G-tetrad ratio higher than 1:1," Nucleic Acids Research, vol. 41, no. 1, pp. 632-638, 2013.

[239] H. L. Wu, C. Y. Hsu, W. H. Liu, and B. Y. Yung, "Berberineinduced apoptosis of human leukemia HL-60 cells is associated with down-regulation of nucleophosmin/B23 and telomerase activity," International Journal of Cancer, vol. 81, pp. 923-929, 1999.

[240] S. Kim, J. Han, N.-Y. Kim et al., "Effect of berberine on p53 expression by TPA in breast cancer cells," Oncology Reports, vol. 27, pp. 210-215, 2012.

[241] H. Zhao, H. D. Halicka, J. Li, and Z. Darzynkiewicz, "Berberine suppresses gero-conversion from cell cycle arrest to senescence," Aging, vol. 5, no. 8, pp. 623-636, 2013.

[242] D. Zhou, L. Shao, W. Feng, J. Chang, and Y. Wang, Compositions and Methods for Selectively Depleting Senescent Cells Comprising Flip, 2016.

[243] Y. Liu, H. Yu, C. Zhang et al., "Protective effects of berberine on radiation-induced lung injury via intercellular adhesion molecular-1 and transforming growth factor-beta-1 in patients with lung cancer," European Journal of Cancer, vol. 44, no. 16, pp. 2425-2432, 2008.

[244] J. Zhang, H. Cao, B. Zhang et al., "Berberine potently attenuates intestinal polyps growth in ApcMin mice and familial adenomatous polyposis patients through inhibition of Wnt signalling," Journal of Cellular and Molecular Medicine, vol. 17, no. 11, pp. 1484-1493, 2013.

[245] U. Bharadwaj, T. K. Eckols, M. Kolosov et al., "Drugrepositioning screening identified piperlongumine as a direct STAT3 inhibitor with potent activity against breast cancer," Oncogene, vol. 34, no. 11, pp. 1341-1353, 2015.

[246] J.-L. Roh, E. H. Kim, J. Y. Park, J. W. Kim, M. Kwon, and B. H. Lee, "Piperlongumine selectively kills cancer cells and increases cisplatin antitumor activity in head and neck cancer," Oncotarget, vol. 5, no. 19, pp. 9227-9238, 2014.

[247] K. Karki, E. Hedrick, R. Kasiappan, U. H. Jin, and S. Safe, "Piperlongumine induces reactive oxygen species (ROS)dependent downregulation of specificity protein transcription factors," Cancer Prevention Research, vol. 10, no. 8, pp. 467-477, 2017.

[248] S.-Y. Chen, G.-H. Liu, W.-Y. Chao et al., "Piperlongumine suppresses proliferation of human oral squamous cell carcinoma through cell cycle arrest, apoptosis and senescence," International Journal of Molecular Sciences, vol. 17, no. 5, p. 616, 2016.
[249] C. Zhu, W. Hu, H. Wu, and X. Hu, "No evident doseresponse relationship between cellular ROS level and its cytotoxicity - a paradoxical issue in ROS-based cancer therapy," Scientific Reports, vol. 4, no. 1, article 5029, 2015.

[250] J. L. Ehren and P. Maher, "Concurrent regulation of the transcription factors Nrf2 and ATF4 mediates the enhancement of glutathione levels by the flavonoid fisetin," Biochemical Pharmacology, vol. 85, no. 12, pp. 1816-1826, 2013.

[251] S. E. Lee, S. I. Jeong, H. Yang, C. S. Park, Y. H. Jin, and Y. S. Park, "Fisetin induces Nrf2-mediated HO-1 expression through PKC- $\delta$ and $\mathrm{p} 38$ in human umbilical vein endothelial cells," Journal of Cellular Biochemistry, vol. 112, no. 9, pp. 2352-2360, 2011.

[252] D. N. Syed, J.-C. Chamcheu, M. I. Khan et al., "Fisetin inhibits human melanoma cell growth through direct binding to p70S6K and mTOR: findings from 3-D melanoma skin equivalents and computational modeling," Biochemical Pharmacology, vol. 89, no. 3, pp. 349-360, 2014.

[253] Y. Suh, F. Afaq, N. Khan, J. J. Johnson, F. H. Khusro, and H. Mukhtar, "Fisetin induces autophagic cell death through suppression of mTOR signaling pathway in prostate cancer cells," Carcinogenesis, vol. 31, no. 8, pp. 1424-1433, 2010.

[254] D. Ash, M. Subramanian, A. Surolia, and C. Shaha, "Nitric oxide is the key mediator of death induced by fisetin in human acute monocytic leukemia cells," American Journal of Cancer Research, vol. 5, no. 2, pp. 481-497, 2015.

[255] Y. Suh, F. Afaq, J. J. Johnson, and H. Mukhtar, "A plant flavonoid fisetin induces apoptosis in colon cancer cells by inhibition of COX2 and Wnt/EGFR/NF- $\kappa$ B-signaling pathways," Carcinogenesis, vol. 30, no. 2, pp. 300-307, 2008.

[256] A. Q. Haddad, N. Fleshner, C. Nelson et al., "Antiproliferative mechanisms of the flavonoids $2,2^{\prime}$-Dihydroxychalcone and fisetin in human prostate cancer cells," Nutrition and Cancer, vol. 62, no. 5, pp. 668-681, 2010.

[257] V. P. Vineetha, R. S. Soumya, and K. G. Raghu, "Phloretin ameliorates arsenic trioxide induced mitochondrial dysfunction in $\mathrm{H} 9 \mathrm{c} 2$ cardiomyoblasts mediated via alterations in membrane permeability and ETC complexes," European Journal of Pharmacology, vol. 754, pp. 162-172, 2015.

[258] C.-H. Wu, Y.-S. Ho, C.-Y. Tsai et al., "In vitro and in vivo study of phloretin-induced apoptosis in human liver cancer cells involving inhibition of type II glucose transporter," International Journal of Cancer, vol. 124, no. 9, pp. 22102219, 2009.

[259] L. Ma, R. Wang, Y. Nan, W. Li, Q. Wang, and F. Jin, "Phloretin exhibits an anticancer effect and enhances the anticancer ability of cisplatin on non-small cell lung cancer cell lines by regulating expression of apoptotic pathways and matrix metalloproteinases," International Journal of Oncology, vol. 48, pp. 843-853, 2015.

[260] J. Min, K. Huang, H. Tang et al., "Phloretin induces apoptosis of non-small cell lung carcinoma A549 cells via JNK1/2 and p38 MAPK pathways," Oncology Reports, vol. 34, no. 6, pp. 2871-2879, 2015.

[261] Y. Liu, C. Fan, L. Pu et al., "Phloretin induces cell cycle arrest and apoptosis of human glioblastoma cells through the generation of reactive oxygen species," Journal of Neuro-Oncology, vol. 128, no. 2, pp. 217-223, 2016.

[262] K. Kunimasa, T. Nagano, Y. Shimono et al., "Glucose metabolism-targeted therapy and withaferin a are effective for epidermal growth factor receptor tyrosine kinase 
inhibitor-induced drug-tolerant persisters," Cancer Science, vol. 108, no. 7, pp. 1368-1377, 2017.

[263] S. Chian, R. Thapa, Z. Chi, X. J. Wang, and X. Tang, "Luteolin inhibits the Nrf2 signaling pathway and tumor growth in vivo," Biochemical and Biophysical Research Communications, vol. 447, no. 4, pp. 602-608, 2014.

[264] A.-M. Gao, Z.-P. Ke, F. Shi, G. C. Sun, and H. Chen, "Chrysin enhances sensitivity of BEL-7402/ADM cells to doxorubicin by suppressing PI3K/Akt/Nrf2 and ERK/Nrf2 pathway," Chemico-Biological Interactions, vol. 206, no. 1, pp. 100108, 2013.

[265] A.-M. Gao, Z.-P. Ke, J.-N. Wang, J. Y. Yang, S. Y. Chen, and H. Chen, "Apigenin sensitizes doxorubicin-resistant hepatocellular carcinoma BEL-7402/ADM cells to doxorubicin via inhibiting PI3K/Akt/Nrf2 pathway," Carcinogenesis, vol. 34, no. 8, pp. 1806-1814, 2013.

[266] S.-W. Ryu, J. H. Woo, Y.-H. Kim, Y. S. Lee, J. W. Park, and Y. S. Bae, "Downregulation of protein kinase CKII is associated with cellular senescence," FEBS Letters, vol. 580, no. 3, pp. 988-994, 2006.

[267] M. S. Yates, Q. T. Tran, P. M. Dolan et al., "Genetic versus chemoprotective activation of Nrf2 signaling: overlapping yet distinct gene expression profiles between Keap1 knockout and triterpenoid-treated mice," Carcinogenesis, vol. 30, no. 6, pp. 1024-1031, 2009.

[268] S. S. Ray and H. I. Swanson, "Dioxin-induced immortalization of normal human keratinocytes and silencing of p53 and p16INK4a," Journal of Biological Chemistry, vol. 279, no. 26, pp. 27187-27193, 2004.

[269] A. M. Brinkman, J. Wu, K. Ersland, and W. Xu, "Estrogen receptor $\alpha$ and aryl hydrocarbon receptor independent growth inhibitory effects of aminoflavone in breast cancer cells," BMC Cancer, vol. 14, no. 1, p. 344, 2014.

[270] M. Contador-Troca, A. Alvarez-Barrientos, E. Barrasa et al., "The dioxin receptor has tumor suppressor activity in melanoma growth and metastasis," Carcinogenesis, vol. 34, no. 12, pp. 2683-2693, 2013.

[271] Y. Fan, G. P. Boivin, E. S. Knudsen, D. W. Nebert, Y. Xia, and A. Puga, "The aryl hydrocarbon receptor functions as a tumor suppressor of liver carcinogenesis," Cancer Research, vol. 70, no. 1, pp. 212-220, 2010.

[272] W. Miao, L. Hu, P. J. Scrivens, and G. Batist, “Transcriptional regulation of NF-E2 p45-related factor (NRF2) expression by the aryl hydrocarbon receptor-xenobiotic response element signaling pathway: direct cross-talk between phase I and II drug-metabolizing enzymes," Journal of Biological Chemistry, vol. 280, no. 21, pp. 20340-20348, 2005.

[273] P.-H. Pang, Y.-H. Lin, Y.-H. Lee, H. H. Hou, S. P. Hsu, and S. H. Juan, "Molecular mechanisms of p21 and p27 induction by 3-methylcholanthrene, an aryl-hydrocarbon receptor agonist, involved in antiproliferation of human umbilical vascular endothelial cells," Journal of Cellular Physiology, vol. 215, no. 1, pp. 161-171, 2008.

[274] B. Rotblat, G. Melino, and R. A. Knight, "NRF2 and p53: Januses in cancer?," Oncotarget, vol. 3, no. 11, pp. 12721283,2012

[275] A. You, C.-W. Nam, N. Wakabayashi, M. Yamamoto, T. W. Kensler, and M. K. Kwak, "Transcription factor Nrf2 maintains the basal expression of Mdm2: an implication of the regulation of p53 signaling by Nrf2," Archives of Biochemistry and Biophysics, vol. 507, no. 2, pp. 356-364, 2011.
[276] M. W. Gordon, F. Yan, X. Zhong et al., "Regulation of p53targeting microRNAs by polycyclic aromatic hydrocarbons: implications in the etiology of multiple myeloma," Molecular Carcinogenesis, vol. 54, no. 10, pp. 1060-1069, 2015.

[277] G. Eades, M. Yang, Y. Yao, Y. Zhang, and Q. Zhou, "miR200a regulates Nrf2 activation by targeting Keap1 mRNA in breast cancer cells," Journal of Biological Chemistry, vol. 286, no. 47, pp. 40725-40733, 2011.

[278] S. Kagawa, M. Natsuizaka, K. A. Whelan et al., "Cellular senescence checkpoint function determines differential Notch1-dependent oncogenic and tumor-suppressor activities," Oncogene, vol. 34, pp. 2347-2359, 2015.

[279] I. Sörensen-Zender, S. Rong, N. Susnik et al., "Renal tubular notch signaling triggers a prosenescent state after acute kidney injury," American Journal of Physiology Renal Physiology, vol. 306, no. 8, pp. F907-F915, 2014.

[280] Y.-C. Huang, H. Hasegawa, S.-W. Wang et al., "Jun dimerization protein 2 controls senescence and differentiation via regulating histone modification," Journal of Biomedicine \& Biotechnology, vol. 2011, Article ID 569034, 13 pages, 2011.

[281] S. Tanigawa, C. H. Lee, C. S. Lin et al., "Jun dimerization protein 2 is a critical component of the Nrf2/MafK complex regulating the response to ROS homeostasis," Cell Death \& Disease, vol. 4, no. 11, article e921, 2013.

[282] M. G. Vander Heiden, L. C. Cantley, and C. B. Thompson, "Understanding the Warburg effect: the metabolic requirements of cell proliferation," Science, vol. 324, no. 5930, pp. 1029-1033, 2009.

[283] S. Jin, R. S. DiPaola, R. Mathew, and E. White, "Metabolic catastrophe as a means to cancer cell death," Journal of Cell Science, vol. 120, no. 3, pp. 379-383, 2007.

[284] L. B. Sullivan and N. S. Chandel, "Mitochondrial reactive oxygen species and cancer," Cancer \& Metabolism, vol. 2, no. 1, p. 17, 2014.

[285] B. Hampel, F. Malisan, H. Niederegger, R. Testi, and P. Jansen-Dürr, "Differential regulation of apoptotic cell death in senescent human cells," Experimental Gerontology, vol. 39, no. 11-12, pp. 1713-1721, 2004.

[286] S. N. Cheuvront, B. R. Ely, R. W. Kenefick, B. B. MichniakKohn, J. C. Rood, and M. N. Sawka, "No effect of nutritional adenosine receptor antagonists on exercise performance in the heat," American Journal of Physiology Regulatory, Integrative and Comparative Physiology, vol. 296, no. 2, pp. R394-R401, 2008.

[287] J. Chang, Y. Wang, L. Shao et al., "Clearance of senescent cells by ABT263 rejuvenates aged hematopoietic stem cells in mice," Nature Medicine, vol. 22, no. 1, pp. 78-83, 2016.

[288] D. A. Gewirtz, S. E. Holt, and L. W. Elmore, "Accelerated senescence: an emerging role in tumor cell response to chemotherapy and radiation," Biochemical Pharmacology, vol. 76, no. 8, pp. 947-957, 2008.

[289] W. Hua, L. Ding, Y. Chen, B. Gong, J. He, and G. Xu, "Determination of berberine in human plasma by liquid chromatography-electrospray ionization-mass spectrometry," Journal of Pharmaceutical and Biomedical Analysis, vol. 44, pp. 931-937, 2007.

[290] Y.-H. Lee, B. S. Kang, and Y.-S. Bae, "Premature senescence in human breast cancer and colon cancer cells by tamoxifen-mediated reactive oxygen species generation," Life Sciences, vol. 97, no. 2, pp. 116-122, 2014. 
[291] J. L. Ryan, C. E. Heckler, M. Ling et al., "Curcumin for radiation dermatitis: a randomized, double-blind, placebo-controlled clinical trial of thirty breast cancer patients," Radiation Research, vol. 180, no. 1, pp. 34-43, 2013.

[292] J. Ji, Y. Tian, Y. Zhu et al., "Ionizing irradiation inhibits keloid fibroblast cell proliferation and induces premature cellular senescence," The Journal of Dermatology, vol. 42, no. 1, pp. 56-63, 2015.

[293] M. Kanai, Y. Otsuka, K. Otsuka et al., "A phase I study investigating the safety and pharmacokinetics of highly bioavailable curcumin (Theracurmin ${ }^{\circledR}$ ) in cancer patients," Cancer Chemotherapy and Pharmacology, vol. 71, no. 6, pp. 15211530, 2013.

[294] D. E. Modrak, E. Leon, D. M. Goldenberg, and D. V. Gold, "Ceramide regulates gemcitabine-induced senescence and apoptosis in human pancreatic cancer cell lines," Molecular Cancer Research, vol. 7, no. 6, pp. 890-896, 2009.

[295] R. Epelbaum, M. Schaffer, B. Vizel, V. Badmaev, and G. Bar-Sela, "Curcumin and gemcitabine in patients with advanced pancreatic cancer," Nutrition and Cancer, vol. 62, no. 8, pp. 1137-1141, 2010.

[296] M. Bayet-Robert, F. Kwiatkowski, M. Leheurteur et al., "Phase I dose escalation trial of docetaxel plus curcumin in patients with advanced and metastatic breast cancer," Cancer Biology \& Therapy, vol. 9, no. 1, pp. 8-14, 2010.

[297] S. R. Schwarze, F. VX, J. A. Desotelle, J. A. Desotelle, M. L. Kenowski, and D. F. Jarrard, "The identification of senescence-specific genes during the induction of senescence in prostate cancer cells," Neoplasia, vol. 7, no. 9, pp. 816-823, 2005.

[298] N. Dhillon, B. B. Aggarwal, R. A. Newman et al., "Phase II trial of curcumin in patients with advanced pancreatic cancer," Clinical Cancer Research, vol. 14, no. 14, pp. 44914499, 2008.

[299] R. A. Sharma, H. R. McLelland, K. A. Hill et al., "Pharmacodynamic and pharmacokinetic study of oral Curcuma extract in patients with colorectal cancer," Clinical Cancer Research, vol. 7, no. 7, pp. 1894-1900, 2001.

[300] X. Wang, S. C. Wong, J. Pan et al., "Evidence of cisplatininduced senescent-like growth arrest in nasopharyngeal carcinoma cells," Cancer Research, vol. 58, no. 22, pp. 50195022, 1998.

[301] A. Litwiniec, L. Gackowska, A. Helmin-Basa, A. Żuryń, and A. Grzanka, "Low-dose etoposide-treatment induces endoreplication and cell death accompanied by cytoskeletal alterations in A549 cells: does the response involve senescence? The possible role of vimentin," Cancer Cellular International, vol. 13, no. 1, p. 9, 2013.

[302] D. Trudel, D. P. Labbé, M. Araya-Farias et al., “A two-stage, single-arm, phase II study of EGCG-enriched green tea drink as a maintenance therapy in women with advanced stage ovarian cancer," Gynecologic Oncology, vol. 131, no. 2, pp. 357-361, 2013.

[303] R. S. Roberson, S. J. Kussick, E. Vallieres, S. Y. J. Chen, and $\mathrm{D} . \mathrm{Y} . \mathrm{Wu}$, "Escape from therapy-induced accelerated cellular senescence in p53-null lung cancer cells and in human lung cancers," Cancer Research, vol. 65, no. 7, pp. 2795-2803, 2005.

[304] T. D. Shanafelt, T. G. Call, C. S. Zent et al., "Phase 2 trial of daily, oral polyphenon $\mathrm{E}$ in patients with asymptomatic, rai stage 0 to II chronic lymphocytic leukemia," Cancer, vol. 119, no. 2, pp. 363-370, 2013.
[305] E. Choan, R. Segal, D. Jonker et al., "A prospective clinical trial of green tea for hormone refractory prostate cancer: an evaluation of the complementary/alternative therapy approach," Urologic Oncology, vol. 23, no. 2, pp. 108-113, 2005.

[306] A. Jatoi, N. Ellison, P. A. Burch et al., "A phase II trial of green tea in the treatment of patients with androgen independent metastatic prostate carcinoma," Cancer, vol. 97, no. 6, p. 1442, 2003.

[307] M. Cruz-Correa, D. A. Shoskes, P. Sanchez et al., "Combination treatment with curcumin and quercetin of adenomas in familial adenomatous polyposis," Clinical Gastroenterology and Hepatology, vol. 4, no. 8, pp. 1035-1038, 2006.

[308] J.-M. Löhr, M. Karimi, B. Omazic et al., “A phase I dose escalation trial of AXP107-11, a novel multi-component crystalline form of genistein, in combination with gemcitabine in chemotherapy-naive patients with unresectable pancreatic cancer," Pancreatology, vol. 16, no. 4, pp. 640-645, 2016.

[309] B. Lazarevic, G. Boezelijn, L. M. Diep et al., "Efficacy and safety of short-term genistein intervention in patients with localized prostate cancer prior to radical prostatectomy: a randomized, placebo-controlled, double-blind phase 2 clinical trial," Nutrition and Cancer, vol. 63, no. 6, pp. 889-898, 2011.

[310] B. Lazarevic, C. Hammarström, J. Yang et al., "The effects of short-term genistein intervention on prostate biomarker expression in patients with localised prostate cancer before radical prostatectomy," British Journal of Nutrition, vol. 108, no. 12, pp. 2138-2147, 2012.

[311] R. Krętowski, M. Borzym-Kluczyk, and M. CechowskaPasko, "Hypoxia enhances the senescence effect of bortezomib-the proteasome inhibitor-on human skin fibroblasts," BioMed Research International, vol. 2014, Article ID 196249, 9 pages, 2014.

[312] T. W. Flaig, D. L. Gustafson, L.-J. Su et al., "A phase I and pharmacokinetic study of silybin-phytosome in prostate cancer patients," Investigational New Drugs, vol. 25, no. 2, pp. 139-146, 2007.

[313] Z. Zhang, Y. Li, and Z. Jiao, "Effect of local application of allicinvia gastroscopy on cell proliferation and apoptosis of progressive gastric carcinoma," Zhongguo Zhong xi yi jie he za zhi Zhongguo Zhongxiyi jiehe zazhi, vol. 28, no. 2, pp. 108-110, 2008. 


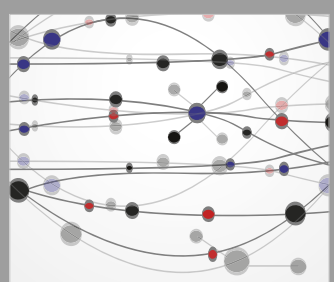

The Scientific World Journal
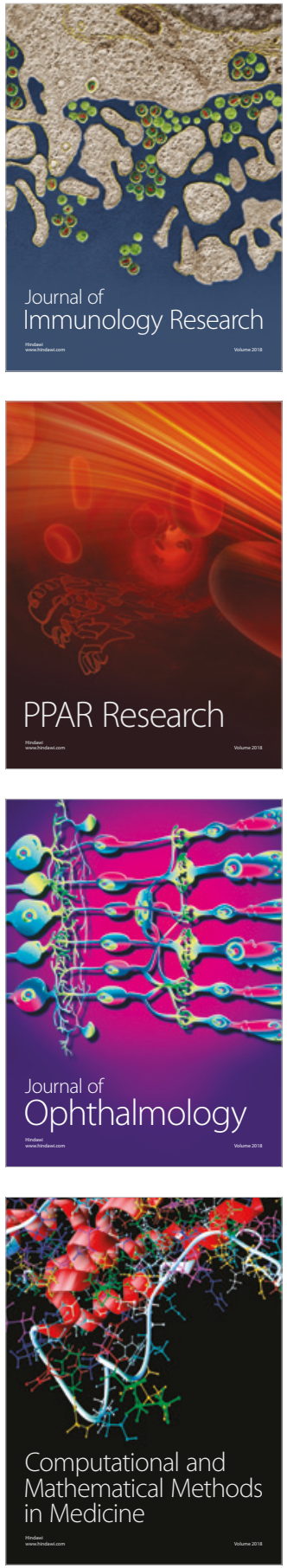

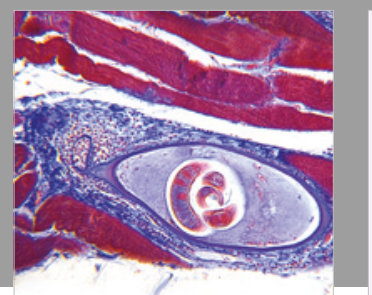

Gastroenterology Research and Practice



\section{Hindawi}

Submit your manuscripts at

www.hindawi.com
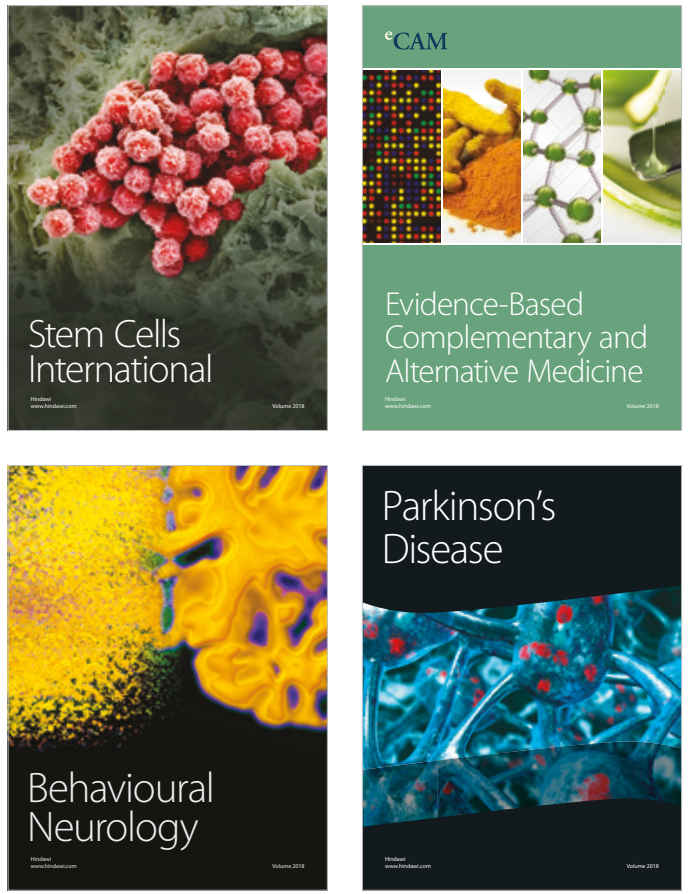



ournal of

Diabetes Research

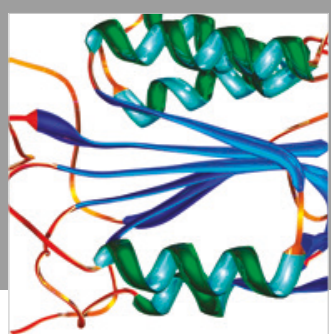

Disease Markers
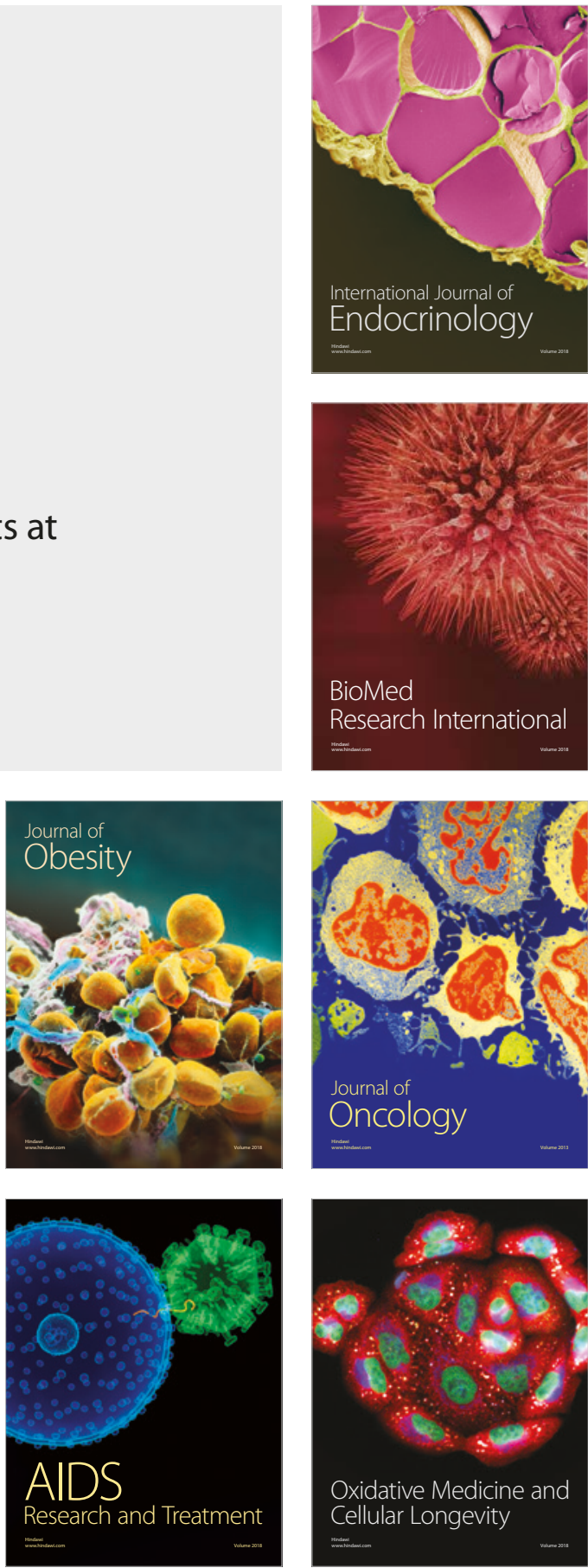